\title{
Wnt Signaling in Neuromuscular Junction Development
}

\author{
Kate Koles and Vivian Budnik \\ Department of Neurobiology, University of Massachusetts Medical School, Worcester, Massachusetts 01605 \\ Correspondence: vivian.budnik@umassmed.edu
}

Wnt proteins are best known for their profound roles in cell patterning, because they are required for the embryonic development of all animal species studied to date. Besides regulating cell fate, Wnt proteins are gaining increasing recognition for their roles in nervous system development and function. New studies indicate that multiple positive and negative Wnt signaling pathways take place simultaneously during the formation of vertebrate and invertebrate neuromuscular junctions. Although some Wnts are essential for the formation of NMJs, others appear to play a more modulatory role as part of multiple signaling pathways. Here we review the most recent findings regarding the function of Wnts at the NMJ from both vertebrate and invertebrate model systems.

W nt proteins are evolutionarily conserved, secreted lipo-glycoproteins involved in a wide range of developmental processes in all metazoan organisms examined to date. In addition to governing many embryonic developmental processes, Wnt signaling is also involved in nervous system maintenance and function, and deregulation of Wnt signaling pathways occurs in many neurodegenerative and psychiatric diseases (De Ferrari and Inestrosa 2000; Caricasole et al. 2005; Okerlund and Cheyette 2011). The first link between Wnt signaling and synapse development was established by Salinas and colleagues in the vertebrate nervous system (Lucas and Salinas 1997; Hall et al. 2000) and by Budnik and colleagues at the invertebrate neuromuscular junction (NMJ) (Packard et al. 2002). Since then, Wnt signaling has emerged as an essential regulator of synaptic development and function in both central and peripheral synapses. Al- though important roles for Wnt signaling have become known from studies in both the central and peripheral nervous system, this article is concerned with the role of Wnts at the NMJ.

\section{WNT LIGANDS, RECEPTORS, AND WNT SIGNALING PATHWAYS}

Wnts and their receptors comprise a large family of proteins. (For a description of these families, see He [2012], Willert and Nusse [2012], and www.stanford.edu/group/nusselab/cgibin/wnt.) Frizzled receptors form a functional heterocomplex with members of the low-density lipoprotein receptor (LDLR)-related protein (LRP) family, Lrp5 and Lrp6 (Pinson et al. 2000; Tamai et al. 2000) and its Drosophila homolog, Arrow (Wehrli et al. 2000). Furthermore, there are families of proteins belonging to the unconventional Wnt receptors, such as

Editors: Roel Nusse, Xi He, and Renee van Amerongen

Additional Perspectives on Wnt Signaling available at www.cshperspectives.org

Copyright (C) 2012 Cold Spring Harbor Laboratory Press; all rights reserved; doi: 10.1101/cshperspect.a008045

Cite this article as Cold Spring Harb Perspect Biol 2012;4:a008045 
members of the ROR (receptor tyrosine kinaselike orphan receptor) (Green et al. 2008) and Derailed (Drl)/Ryk (related to receptor tyrosine kinase) families (Fradkin et al. 2010). Adding to this diversity of ligands and receptors is the number of distinct signaling pathways activated by Wnt ligand/receptor interactions, namely, the canonical Wnt pathway (Logan and Nusse 2004), the divergent canonical Wnt pathway (Ciani et al. 2004), the planar cell polarity (PCP) pathway (Mlodzik 2002), the calcium Wnt signaling pathway (Kuhl et al. 2000), and the Frizzled nuclear import (FNI) Wnt pathway (Speese and Budnik 2007). Given that most of the transduction pathways are described in Cadigan and Peifer (2012), He (2012), Stamos and Weis (2012), and van Amerongen (2012), only a brief description of the pathways is provided in this review, except for the FNI pathway, which so far has only been characterized in the nervous system. In the canonical Wnt pathway, Wnt binding to Frizzled receptors activates Dishevelled (Dvl), which inhibits the phosphorylation of $\beta$-catenin by glycogen synthase kinase $3 \beta$ (Gsk3 $\beta$ ), through the disassembly of a destruction complex, which normally triggers the degradation of cytoplasmic $\beta$-catenin. Wnt binding to Frizzled receptors disrupts this complex, leading to the stabilization of $\beta$ catenin, its import to the nucleus, and the activation of Wnt target genes (Fig. 1A). In the divergent canonical Wnt pathway, Dvl regulates the Gsk3 $\beta$-dependent phosphorylation of microtubule-associated proteins (MAPs), which control the stability of microtubule networks (Fig. 1B) (Lucas et al. 1998; Ciani et al. 2004). The PCP Wnt pathway regulates tissue and cell polarity through a Dvl-dependent activation of small GTPases, such as Rho, Rac, and Jun ami- no-terminal kinase (Jnk) (Fig. 1C). In the Wnt calcium pathway, cell fate decisions and cell movement choices are made via a Dvl-dependent increase in intracellular calcium levels, which leads to the activation of protein kinase $\mathrm{C}$ (PKC) and calcium/calmodulin-dependent protein kinase II (CaMKII), the nuclear import of the nuclear factor of activated T-cells (NFAT) and concomitant changes in gene expression (Fig. 1D). Finally, in the FNI Wnt pathway, Frizzled-2 receptors are endocytosed and trafficked toward the nucleus, where a carboxy-terminal fragment of Frizzed-2 is cleaved and imported into the nucleus (Fig. 1E) (Mathew et al. 2005). Within the nucleus, DFz2C fragments associate with large ribonucleoprotein (RNP) granules, which exit the nucleus through a novel mechanism of nuclear envelope budding, akin to the nuclear egress of Herpes-type viruses (Roller 2008; Speese et al. 2012). The large RNPs contain transcripts encoding postsynaptic proteins, and because these transcripts are also localized at postsynaptic sites, it is presumed that they are involved in local translation (Speese et al. 2012). Indeed, genetic manipulations interfering with the FNI pathway lead to abnormal synaptic growth (Mathew et al. 2005; Speese et al. 2012) (discussed below). A similar pathway of receptor endocytosis, cleavage, and fragment import to the nucleus is observed for the atypical Wnt receptor Ryk (Lyu et al. 2008). However, in this case, the pathway is required for normal cortical neurogenesis, as opposed to synapse development, and the exact role of Ryk receptor fragments within the nucleus has not been investigated. Most importantly, through alternative ligands, receptors, and signaling pathways, Wnts have considerable potential to regulate development differentially.

Figure 1. Overview of Wnt signaling pathways. Wnts signal through Frizzled receptors that can form a complex with Lrp-5/6 receptors. With the exception of the FNI pathway, these signaling pathways activate the scaffolding protein Dishevelled (Dvl). The different pathways diverge downstream from Dvl. ( $A$ ) In the canonical pathway, Dvl disrupts the "destruction complex" composed of Axin, Adenomatous Polyposis Coli (APC), and Gsk3 $\beta$. This prevents the phosphorylation of $\beta$-catenin by Gsk3 $\beta$, which leads to its stabilization and subsequent nuclear import. In the nucleus, $\beta$-catenin associates with the transcription factor T-cell factor/lymphoid enhancer factor 1 (TCF/Lef1) and regulates gene expression. The secreted proteins Dickkopf1 (Dkk1) and secreted Frizzled-related protein (Sfrp) inhibit this pathway. (Legend continues on facing page.) 


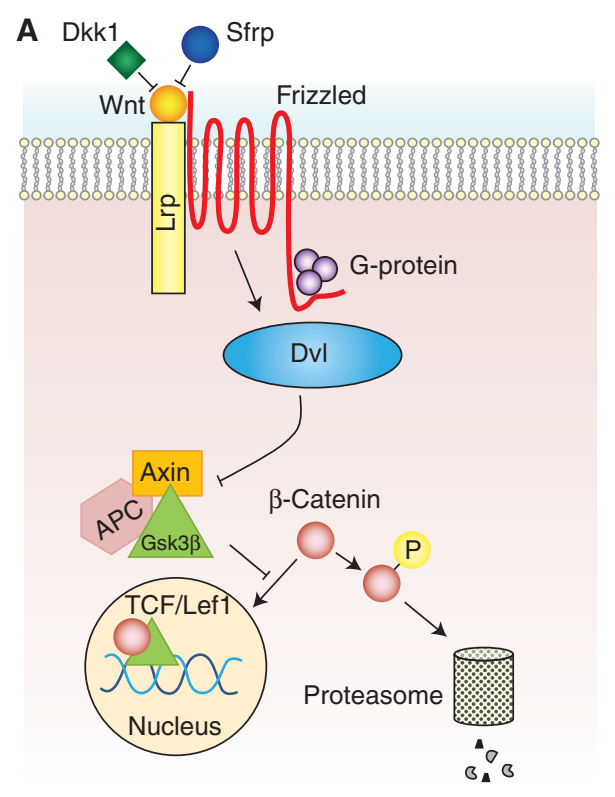

C

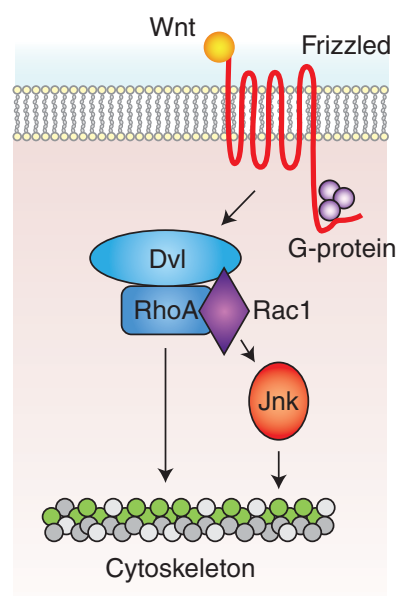

B

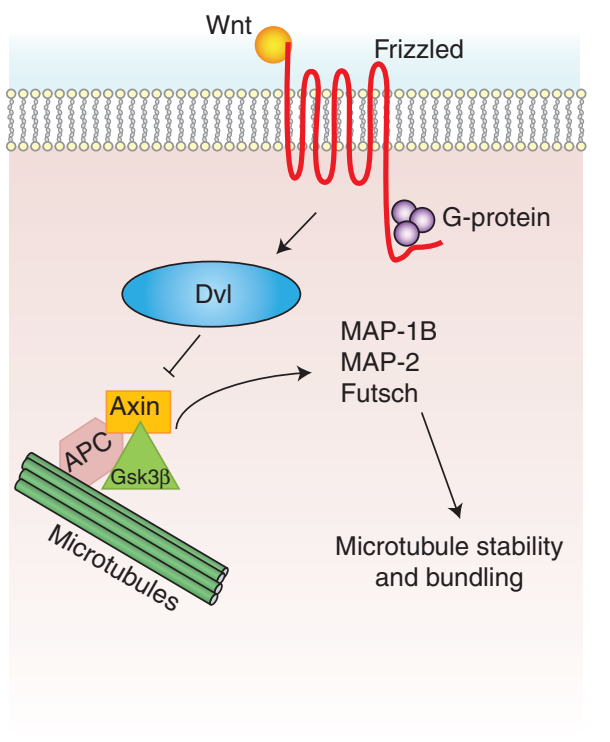

D

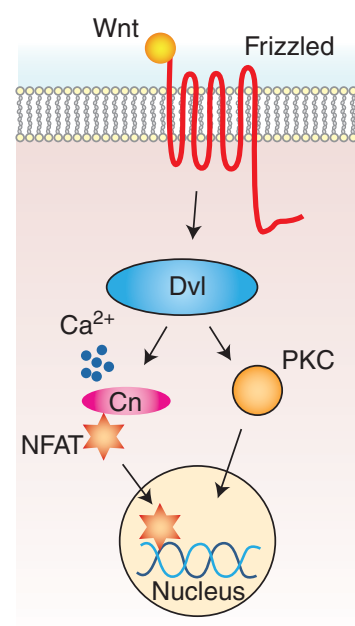

Wnt Signaling in NMJ Development

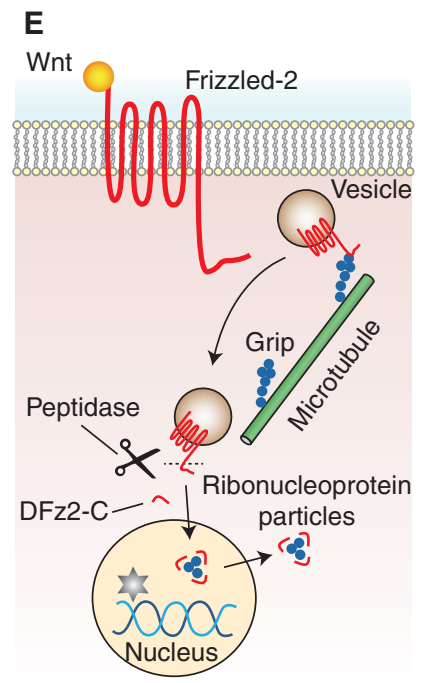

Figure 1. (Continued) (B) Following Wnt activation of the divergent canonical pathway, Dvl inhibits Gsk3 $\beta$, which leads to the decreased phosphorylation of microtubule-associated proteins (MAPs), such as Tau, MAP1B, MAP-2, or the related Drosophila protein Futsch. (C) In the planar cell polarity pathway, Dvl activates the small Rho GTPases RhoA and Rac1, and c-Jun-amino-terminal kinase (Jnk), which leads to the regulation of actin and microtubule cytoskeletons. $(D)$ In the Wnt calcium pathway, Dvl activation leads to a rapid increase in intracellular calcium levels and subsequent activation of calcium-sensitive enzymes such as protein kinase $\mathrm{C}$ (PKC), calcium/calmodulin-dependent protein kinase II (CaMKII) and the $\mathrm{Ca}^{2+}$-activated phosphatase calcineurin $(\mathrm{Cn})$. Calcineurin directly binds to and dephosphorylates nuclear factor of activated T-cells (NFAT), which, in turn, allows their nuclear translocation where they regulate gene expression. (E) In the Frizzled nuclear import pathway (FNI), Wnt binding to Frizzled-2 (DFz2) leads to its endocytosis and Grip-dependent trafficking to the periphery of the nucleus. Here the carboxyl terminus of DFz2 is cleaved and imported. In Drosophila, DFz2-C organizes ribonucleoprotein (RNP) particles containing specific transcripts, which then egress from the nucleus and are likely translated in the cytoplasm. A similar nuclear import pathway has also been described for the atypical Ryk receptor during cortical neurogenesis (Lyu et al. 2008). 


\section{BRIEF OVERVIEW OF VERTEBRATE NMJ DEVELOPMENT}

Vertebrate NMJs are among the longest and best-studied peripheral synaptic units because of their simplicity and accessibility. Motor neuron axons innervate the muscle at the end plate, where axon terminals branch into fine synaptic varicosities, apposed to foldings of the muscle membrane, the junctional folds. The crests of these folds appose presynaptic active zones, the sites of acetylcholine ( $\mathrm{ACh}$ )-containing vesicle exocytosis at presynaptic terminals, and contain a high density of neurotransmitter receptors. In contrast, the valleys of the junctional folds and their basement membrane are enriched in acetylcholinesterase (AChE), which rapidly degrades acetylcholine, thus terminating ACh-induced responses.

Even before nerve innervation, AChR clusters form in a broad band at the muscle midline, a process called AChR prepatterning (Yang et al. 2001). These "preformed" clusters are also called aneural AChR clusters to underscore their formation independently of innervation. Once the motor axon interacts with the muscle, AChR clusters form at postsynaptic regions exactly apposed to the sites of nerve contact. These mature clusters (also called neural AChR clusters) are formed by the recruitment of aneural AChR clusters as well as by the targeted accumulation of newly synthesized AChRs (Sanes and Lichtman 2001).

Despite its relative simplicity, the vertebrate NMJ has provided us with remarkable insight into the mechanisms of synapse development. Adding to the multiple players found to participate in NMJ development is the recent discovery that, not totally unexpectedly, these also include members of the Wnt family.

An important initial discovery in the quest to understand NMJ development was the identification of Agrin, originally isolated from the electric organ of the pacific electric ray (Smith et al. 1987) as a protein that could trigger AChR clustering in cultured myotubes (Wallace 1986). These prolific initial studies also led to the model that Agrin, a heparan sulfate proteoglycan, was secreted by neurons, accumulated in the basal lamina at the synaptic cleft, where it triggered a molecular cascade in the muscle. This signaling cascade led to the phosphorylation of the $\beta$-subunit of $\mathrm{AChR}$ and the redistribution of AChRs to the NMJs in association with a $43-\mathrm{kDa}$ AChR-associated protein. This 43$\mathrm{kDa} A C h R-a s s o c i a t e d$ protein was subsequently identified as Rapsyn (receptor-associated protein at synapses) (Frail et al. 1988). Muscles and Schwann cells were also known to express Agrin, but only the neuronal isoform was sufficiently potent to induce AChR clustering (Gesemann et al. 1995). Interestingly, agrin ${ }^{-/-}$ mice were able to form aneural AChR clusters before innervation, indicating that Agrin was not required for prepatterning (Lin et al. 2001). During NMJ maturation, the preformed AChR clusters outside of the innervated area are dispersed upon acetylcholine release, and from this perspective, Agrin, which prevents the dispersal of neural AChR clusters, can also be considered as an "anti-declustering factor," in addition to its AChR clustering role (Lin et al. 2005; Kummer et al. 2006).

One of the key milestones after the identification of Agrin was cloning its muscle-specific receptor, aptly named muscle-specific kinase (MuSK) (Jennings et al. 1993; Valenzuela et al. 1995; DeChiara et al. 1996; Glass et al. 1996). Unlike Agrin, MuSKwas required for both neural and aneural AChR clustering in mice and zebrafish (Yang et al. 2001; Zhang et al. 2004). Surprisingly, however, during neural AChR clustering, Agrin did not interact directly with MuSK, suggesting the existence of an MASC (myotubeassociated specificity component) (Glass et al. 1996).

\section{WNT SIGNALING AT THE VERTEBRATE NMJ}

It was around this time that a link between NMJ development and Wnt signaling was suspected, because the newly cloned MuSK contained a conserved cysteine-rich domain (CRD) found in Frizzled receptors, and this domain was known to be required for Wnt ligand binding (Masiakowski and Yancopoulos 1998). However, experimental evidence supporting the ability of Wnts to bind the MuSK CRD domain was 
only obtained a decade later (Jing et al. 2009). During the intervening decade, a more pressing challenge had been the identification of the mysterious MASC.

First, Weatherbee et al. (2006) reported that NMJ abnormalities in Lrp4 ${ }^{-/-}$mice had striking similarities to those observed in Musk ${ }^{-/-}$ mutants. Lrp4 is an Lrp family member with an extracellular domain resembling that of Lrp5 and 6/Arrow, but that appears to antagonize Wnt signaling during digit formation in mice (Johnson et al. 2005). Lrp4 has also been shown to interact with postsynaptic density protein 95 (PSD-95) in the brain (Tian et al. 2006). Subsequently, two independent groups reported that Lrp4 was the long-sought Agrin binding receptor (Kim et al. 2008; Zhang et al. 2008). These studies showed that Lrp4 was expressed at NMJs in myotubes, where it bound selectively to the neuronal isoform of Agrin and was necessary for Agrin-induced activation of MuSK and AChR clustering. Indeed, recent detailed structural studies by Zhang and colleagues have now revealed that several of the extracellular domains on Lrp4 serve as ligands for MuSK and that Agrin dramatically stimulates this interaction (Gomez and Burden 2011; Zhang et al. 2011). Following Agrin-stimulated Lrp4 binding to MuSK, the receptor is tyrosine-phosphorylated and recruits Dok-7 (Inoue et al. 2009), a muscle-specific adaptor protein. Like MuSK, Dok-7 is essential for NMJ formation, because in its absence NMJs fail to form, and Dok-7 overexpression dramatically stimulates AChR clustering (Okada et al. 2006). Dok-7 acts through two different pathways determined by its amino-terminal and carboxy-terminal protein interactions. First, Dok-7 dimerizes (Bergamin et al. 2010), and its amino terminus stimulates MuSK activity. However, this activity of Dok-7 only minimally affects postsynaptic differentiation (Hallock et al. 2010). Second, Dok-7, via its carboxyl terminus, also recruits two adaptor proteins, CT10 regulators of kinase, Crk and Crk-L, downstream from MuSK activation (Hallock et al. 2010; Burden 2011), which are required in the muscle for normal presynaptic and postsynaptic NMJ differentiation. In Crk and Crk-L double mutants, motor axon terminals occupied a larger muscle area than controls and had significantly reduced synapse numbers, with several muscle fibers lacking innervation. These mutants die at birth because of the inability to inflate their lungs. Interestingly, many patients with congenital myasthenia have mutations in the carboxyl terminus of Dok-7, and these results provide insight into the possible molecular pathways affected in this disease. Together with Agrin, Rapsyn, MuSK, and Lrp4, Dok-7 represents an indispensable component of the molecular pathway essential for NMJ formation in vertebrates. Numerous additional molecules and pathways involved in the assembly of NMJ have been revealed over the past few years. These are discussed in excellent reviews (Kummer et al. 2006; Wu et al. 2010).

\section{WNTS AS POSITIVE REGULATORS OF NMJ DEVELOPMENT}

The first experimental evidence implicating Wnt signaling in NMJ development was provided when a yeast two-hybrid screen geared to identify intracellular binding partners of MuSK led to the identification of Dishevelled1 (Dvl1), a scaffolding protein activated by several Wnt signaling pathways (Luo et al. 2002). Gainand loss-of-function experiments in vivo and in vitro showed that Dvll was required for the Agrin-mediated clustering of AChRs. In addition, the Dvl1-interacting protein $\mathrm{p} 21$-activated kinase 1 (PAK1) was identified, and it was shown that its activation by Agrin required Dvll. MuSK, Dvl, and PAK1 formed a ternary complex required for AChR clustering in muscle. Furthermore, expression of a Dvll mutant transgene lacking the DEP (Dishevelled-Egl-10-Pleckstrin) domain in muscle cells of Xenopus nerve-muscle cocultures led to decreased spontaneous synaptic current frequency and amplitude, indicating a potential muscle-derived retrograde signal that could influence presynaptic neurotransmitter release (Luo et al. 2002).

Subsequently, it was shown that the $\beta$-subunit but not the $\alpha 1$-, $\alpha 3-, \alpha 7$-, or $\varepsilon$-subunits of AChR interacted with APC, and its function was required in Agrin-induced AChR clustering (Wang et al. 2003). APC is a well-known regulator of $\beta$-catenin, a key effector of canonical 
Wnt signaling (Aoki and Taketo 2007). APC is also known to interact with microtubules, actin filaments, and EB1 (Su et al. 1995), a microtubule plus-end tracking protein that negatively regulates APC-actin interaction (Reilein and Nelson 2005; Moseley et al. 2007). It was suggested that APC supported a cross talk between Agrin- and Wnt-mediated signaling pathways, by coordinating the functions of actin and the microtubule cytoskeleton. Notably, the APC$\mathrm{AChR}$ interaction was not unique to musclespecific AChRs, because APC also regulated the synaptic localization of neuronal $\alpha 3$-nicotinic AChRs by binding to PSD-93, $\beta$-catenin, and EB1 (Temburni et al. 2004; Rosenberg et al. 2008). Furthermore, APC functions presynaptically as well, where it increases the clustering and membrane localization of the $\alpha 7$-nicotinic AChR in response to Wnt-7a signaling (Farias et al. 2007). All of these data implicate APC as a Wnt downstream effector that is crucially involved in the localization of select AChRs both at neuronal and NMJ synapses.

More recently, it was found that Rapsyn binds to $\beta$-catenin (Zhang et al. 2007). Rapsyn has been known to associate with AChRs in an Agrin-dependent manner (Moransard et al. 2003), and, indeed, $\beta$-catenin associated with AChR following Agrin treatment. This Agrintriggered association did not occur in rapsyn ${ }^{-1-}$ mice, indicating that Rapsyn is required for $\beta$-catenin association with AChR. Reducing $\beta$ catenin levels in $\mathrm{C} 2 \mathrm{C} 12$ myotubes by shRNA resulted in decreased AChR clustering following Agrin treatment (Zhang et al. 2007; but see Li et al. 2008). To understand the role of $\beta$-catenin in vivo, $\beta$-catenin was conditionally knocked out only in the muscles of mice. Surprisingly, in addition to muscle-specific phenotypes, such as the increased size and wider distribution of AChR clusters, primary nerve branches were mislocalized, evoked and spontaneous neurotransmitter release was decreased, and shortterm plasticity was abnormal in these mice ( $\mathrm{Li}$ et al. 2008). In contrast, Agrin-induced AChR clustering was unaffected in cultured muscles from $\beta$-catenin ${ }^{-/-}$mice. Most importantly, $\beta$ catenin conditional knockout in neurons did not have any effect on NMJ morphology or function, implying that muscle $\beta$-catenin is involved in presynaptic development and function in an as-yet-unidentified retrograde pathway (Fig. 3) (Li et al. 2008).

In addition to Wnt signaling pathway components, some of the Wnt ligands have also been identified. Whereas Wnt1 (Luo et al. 2002), Wnt4, Wnt6, and Wnt7b (Zhang et al. 2007) were found to have no effect on AChR clustering, Wnt3, which is expressed in mouse motor neurons at the time of innervation (Krylova et al. 2002), enhanced AChR clustering in developing chicken wing NMJs and the clustering ability of Agrin in mouse cultured myotubes (Henriquez et al. 2008). Dickkopf-1 (Dkk1), which specifically blocks canonical Wnt signaling (Fig. 1A) (Niehrs 2006), had no effect, whereas secreted Frizzled-related protein 1 (Sfrp1), which blocks both canonical and noncanonical Wnt signaling (Rattner et al. 1997), reduced the number of AChRs induced by Wnt3, indicating that Wnt3 is likely to mediate this effect via a non-canonical Wnt signaling pathway in myotubes, even though Wnt3 can activate canonical signaling (Barrow et al. 2003). It was also found that Wnt 3 induced a quick, Agrin-independent transient up-regulation of Racl activity, which led to the rapid formation of AChR microclusters (Fig. 2A). These microclusters were subsequently stabilized into fullsized clusters in an Agrin-dependent manner, in a process involving Rho signaling (Fig. 2B) (Weston et al. 2003; Henriquez et al. 2008). These observations led to a model in which Wnt3 released from motor neurons induces the first wave of Racl activation and subsequent AChR microclustering, which is then consolidated into mature AChR clusters via Agrinmediated signaling. Nevertheless, the muscle receptor(s) through which Wnt3 signals this activation remain to be identified.

A role for Wnts in both AChR prepatterning and axon guidance is also provided by studies in zebrafish. As discussed above, before the arrival of motor nerve terminals to the muscle field, AChRs spontaneously cluster in the mid-region of the muscle, where prospective NMJs eventually form, and this prepatterning depends on MuSK (Lin et al. 2001; Yang et al. 2001). 
Wnt Signaling in NMJ Development

A
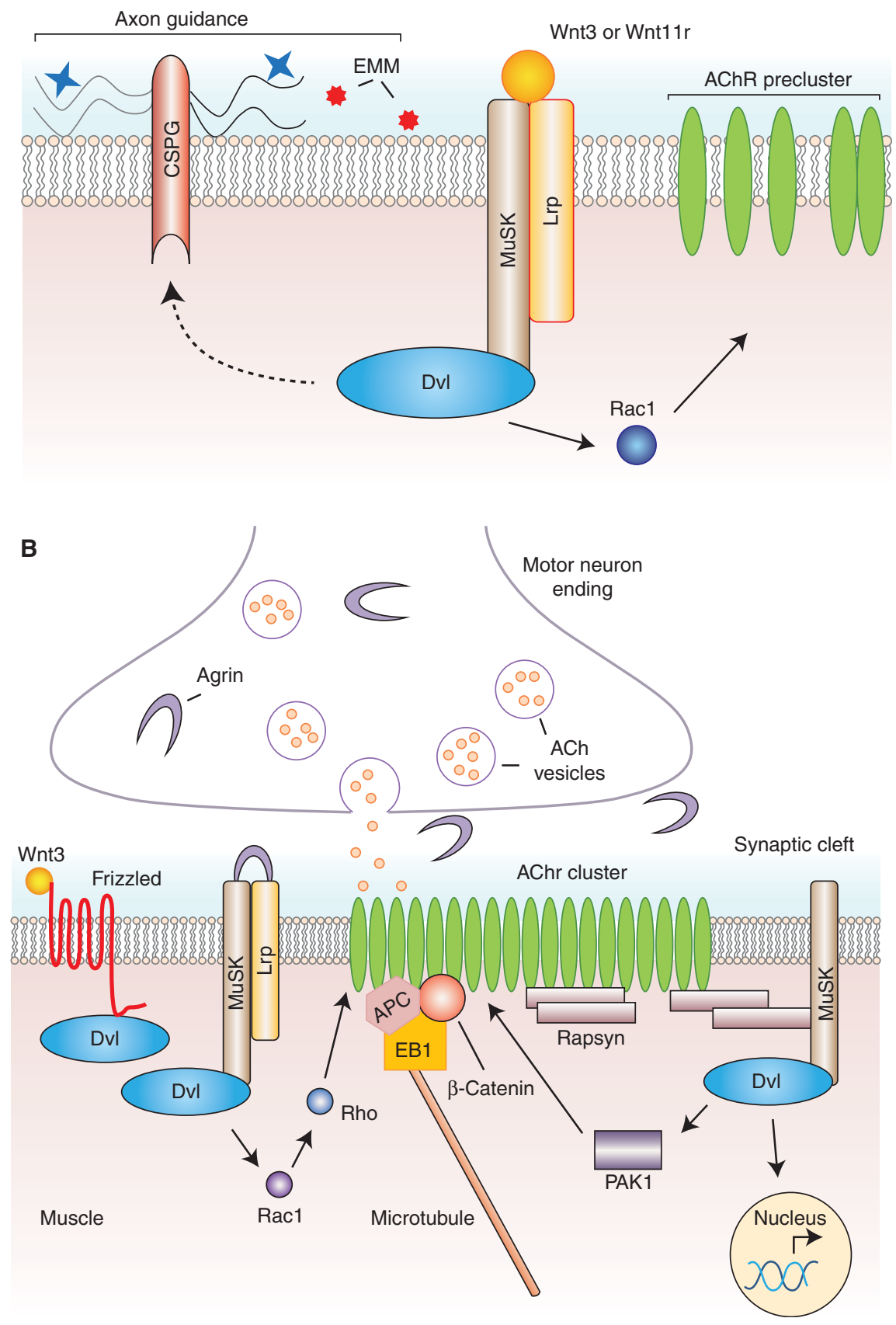

Figure 2. Wnt signaling at vertebrate neuromuscular junctions. (A) Mouse Wnt3 and zebrafish Wnt1 1r function during prepatterning. Wnt11r signaling through Unplugged/MuSK before innervation leads to aneural AChR clustering and also via a parallel signaling pathway to changes in extracellular matrix modifications (EMMs), possibly via chondroitin sulfate proteoglycans (CSPGs) that eventually influence incoming motor neuron axonal growth cone guidance. Wnt3 signaling leads to the rapid and transient activation of Racl and AChR microcluster formation, which $(B)$ in the presence of neural agrin at the time of innervation are stabilized in exact opposition to the presynaptic terminal. 
Many of these aneural clusters are incorporated into neural AChRs clusters upon nerve arrival (Flanagan-Steet et al. 2005). However, the function of prepatterning has been a matter of debate, partly owing to the observations that some nerves can ignore preformed $\mathrm{AChR}$ clusters and initiate NMJ development at new areas (Anderson and Cohen 1977), raising the possibility that the nerve, or nerve-derived factors, are instructive for NMJ formation. Elegant studies by Jing et al. (2009) address this long-standing dilemma. Live imaging of wild-type and MusK $^{-/-}$mutants (which in zebrafish is called "unplugged") revealed that neuronal growth cones explored a wider muscle area and invaded muscle territories that they usually avoid. Because unplugged/MuSK is a muscle-specific gene, these data indicate that muscle plays a role in restricting the area that growth cones explore during innervation. Based on expression time and pattern (spinal cord and adaxial somites) in addition to its mutant phenotype, the investigators identified the nonconventional Wnt11r, as required for AChR prepatterning on the adaxial muscles. Live imaging of motor growth cones revealed that wnt11r morpholino-induced abnormalities in prepatterning were virtually identical to those observed in unplugged/MuSK ${ }^{-/}$mutants, suggesting that Wnt11r might act through unplugged/MuSK. In contrast, neurally induced AChR clusters were formed and developed normally in wnt11r morpholino-treated animals, suggesting that Wnt11r function is restricted to prepatterning. That Wnt11r and Unplugged/MuSK were mutually required for prepatterning was confirmed by showing genetic interactions between the genes. In addition, by using rescue experiments with the short (containing the CRD and Kringle domains) or the long (containing three amino-terminal Ig domains in addition to CRD and Kringle domains) Unplugged, it was shown that the CRD domain of Unplugged/MuSK was required for physical interaction between Wnt11r and Unplugged. Expressing a Dvl isoform that interferes with non-canonical Wnt signaling also led to prepatterning defects, implicating it in the signaling pathway downstream from Wnt11r.
Interestingly, in the absence of prepatterning, neurally induced AChR clusters and functional NMJs were formed, albeit being slightly smaller. However, in the absence of prepatterning, axonal growth cones were not directed to the narrower mid-region of the prospective NMJs, and they explored much broader muscle areas. The investigators conclude that one of the functions of prepatterning is to guide incoming axons (perhaps via the Wnt11r or Unplugged signaling-induced modifications to the extracellular matrix) and to restrict muscle AChRs cluster formation to a common muscle area for efficient NMJ formation (Fig. 2A) (Jing et al. 2009).

\section{NEGATIVE REGULATION OF NMJs BY WNT}

Negative regulation of $\mathrm{AChR}$ clustering by Wnts has also been documented. Wnt3a expression in the muscle gradually increases during the phase of embryogenesis that coincides with NMJ development (Wang et al. 2008). However, pretreatment of cultured myotubes with Wnt3a-containing conditioned medium before Agrin application significantly reduced AChR aggregation. Moreover, transfection of C2C12 myotubes with Wnt3a, but not Wnt5, Wnt7a, or Wnt11, reduced Agrin-mediated AChR clustering. Transfection with Dkk1, which antagonizes the canonical Wnt pathway, increased AChR clustering, indicating that canonical Wnt signaling negatively regulates NMJ development. The stability of AChR clusters was also reduced when Wnt3a was applied after Agrin-induced clustering. The effects of Wnt 3 a were mediated via $\beta$-catenin and resulted in reduced Rapsyn expression. Reduction of $\beta$-catenin by shRNA resulted in decreased Agrin-dependent AChR clustering, likely because of the disrupted $\beta$-catenin-Rapsyn interaction (Zhang et al. 2008) or the increased Rapsyn expression (Yoshihara and Hall 1993; Wang et al. 2008). Downstream from Wnt3a, $\beta$-catenin is known to function as a cotranscription factor with TCF (Korinek et al. 1997). However, dominant negative TCF had no effect on AChR clustering, indicating that $\beta$-catenin function is independent of TCF-mediated 
Wnt Signaling in NMJ Development

transcription (Zhang et al. 2007; Li et al. 2008). These results indicate that muscle Wnt3a disperses AChR clusters by down-regulating Rapsyn expression in a $\beta$-catenin-dependent manner (Fig. 3). In a larger context, these observations highlight the importance of both positive and negative Wnt signals in sculpting the mature NMJ.

In summary, Wnt proteins have been found to play multiple roles in all stages of vertebrate NMJ formation, both in the form of positive and negative signaling pathways. At least two Wnts, muscle Wnt3 and non-muscle Wnt11r, acting through non-canonical pathways, appear to function during prepatterning predominantly by modulating AChR precluster formation, which are subsequently stabilized into mature AChRs in an agrin-dependent manner. In contrast, Wnt3a induces the dispersal of AChR clusters in the presence of Agrin, suggesting that the balance of positive and negative signaling pathways is at work during NMJ development.

\section{WNT SIGNALING AT INVERTEBRATE NMJS}

Two invertebrate systems, Drosophila melanogaster (fruit fly) and Caenorhabditis elegans (roundworm), have been influential in uncovering the function of Wnt family molecules at the neuromuscular junction (NMJ). The ease of genetic manipulation in these relatively simple and highly accessible model organisms has provided a wealth of groundbreaking insight into the development and plasticity of NMJs.

\section{THE ROLE OF WNTs AT THE LARVAL NMJ OF DROSOPHILA}

Drosophila larvae offer an exceptionally accessible model system to study the development and plasticity of NMJs. The larval body wall muscles are innervated by excitatory glutamatergic motor neurons that terminate in stereotypical NMJs with easily discernible synaptic boutons. In response to the rapid growth of the larva and the consequent growth of its body wall muscle

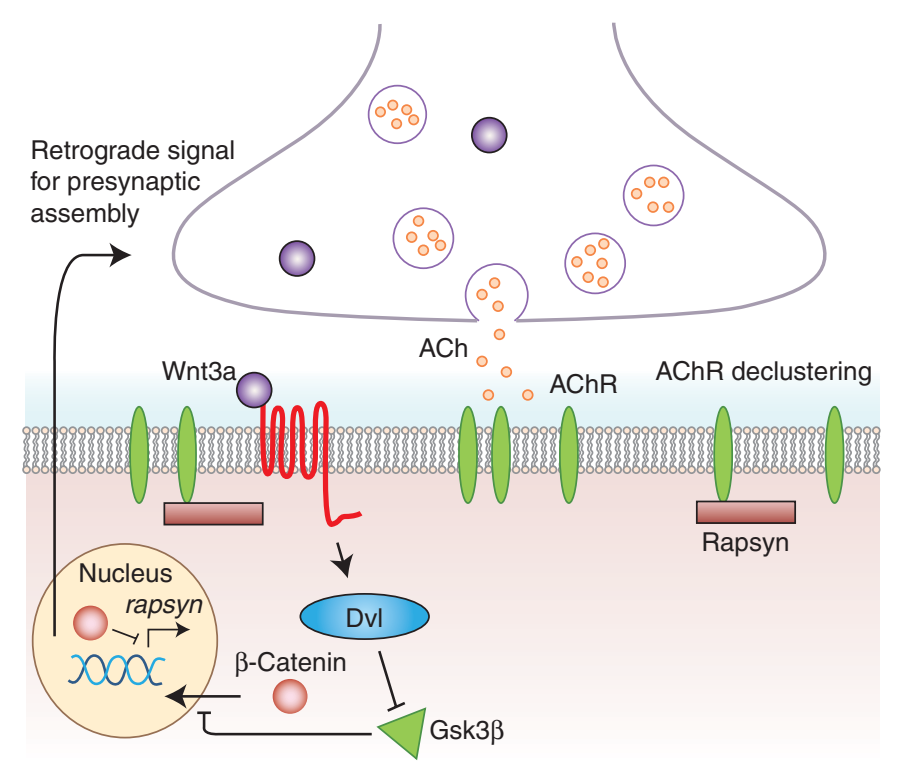

Figure 3. Negative regulation of AChR clustering by Wnt3a. Muscle Wnt3a initiates a Wnt signaling pathway in the muscle that leads to decreased Rapsyn levels. This is achieved through the $\beta$-catenin-mediated negative regulation of rapsyn gene expression, and decreased Rapsyn levels result in the destabilization and dispersal of AChR clusters. In addition, Wnt3a, via $\beta$-catenin, also triggers an unknown retrograde signal that affects presynaptic function and/or assembly. 
cells after hatching from the egg, NMJs show a 10 -fold increase in synaptic bouton number and size during larval development (Gorczyca et al. 1993; Schuster et al. 1996). In addition, larval NMJs undergo structural and functional modifications in response to experience and electrical activity (Budnik et al. 1990; Sigrist et al. 2003; Steinert et al. 2006; Ataman et al. 2008; Koon et al. 2011), offering a powerful experimental system to study the molecular processes underlying synaptic growth and plasticity.

A role for Drosophila Wnt1, Wingless (Wg), in NMJ development was first discovered by Packard et al. (2002), when they found that $\mathrm{Wg}$ was present at synaptic boutons of the $\mathrm{NMJ}$ and that transient reduction in Wg secretion prevented NMJ expansion during muscle growth (Packard et al. 2002). NMJs from these temperature-sensitive $w g$ mutants $\left(w g^{t s}\right)$ shifted to restrictive temperature for $12-18 \mathrm{~h}$ during late larval development, also had NMJs containing unusually large and irregularly shaped boutons. These abnormal boutons also displayed abnormal distribution of glutamate receptor subunit, DGluRIIA, and the PDZ protein of the PSD95-family Discs-Large (Dlg). Most strikingly, several synaptic boutons, later called "ghost boutons" (Ataman et al. 2006), were filled with synaptic vesicles yet lacked mitochondria, presynaptic active zones, and the postsynaptic subsynaptic reticulum (SSR) (Packard et al. 2002). These ghost boutons were later found to be devoid of any postsynaptic protein and lacked most labeling for the active-zone protein Bruchpilot (Brp) (Ataman et al. 2006, 2008; Korkut et al. 2009). Live imaging of NMJs during acute elevation of synaptic activity, which resulted in rapid formation of ghost boutons, together with the observation that ghost boutons are also observed at wild-type NMJs, albeit at very low frequencies (Ataman et al. 2008), led to the conclusion that ghost boutons are a normal undifferentiated stage during the development of synaptic boutons. In Wnt mutants, the differentiation of ghost boutons is blocked, leading to a reduced number of boutons and the accumulation of ghost boutons.

The presynaptic microtubule cytoskeleton at the NMJ was also altered, because labeling
NMJs with the microtubule-associated protein 1B (MAP-1B)-related protein Futsch, which is phosphorylated by Gsk3 $\beta$ /Shaggy (Sgg) (Gogel et al. 2006), revealed abnormal microtubule bundling (Packard et al. 2002). Wild-type NMJs display a characteristic proportion of microtubule loops (thought to be stable microtubule bundles), splayed microtubule bundles, and fragmented microtubules (both likely representing microtubules undergoing remodeling) throughout NMJ branches (Roos et al. 2000; Packard et al. 2002; Ruiz-Canada et al. 2004). However, the proportion of looped, splayed, and fragmented microtubules was altered in the $w g$ mutant (Packard et al. 2002), again suggesting an abnormal development of the NMJ cytoskeleton in the absence of Wg signaling.

These defects were shown to be mediated by the Wg receptor Drosophila Frizzled-2 (DFz2) (Packard et al. 2002; Ataman et al. 2006) and its coreceptor Arrow/Lrp5/6 (low-density lipoprotein receptor-related protein) (Miech et al. 2008). These receptors are likely to function both presynaptically in the motor neurons and postsynaptically in the muscle. Efforts to delineate the exact signaling pathway triggered by $\mathrm{Wg}$ release led to the finding that $\mathrm{Wg}$, likely released by synaptic boutons (Packard et al. 2002), activated alternative signaling pathways in the presynaptic motor neurons and the postsynaptic muscles (Ataman et al. 2008; Miech et al. 2008). Activation of the $\mathrm{Wg}$ pathway in the presynaptic compartment appeared to activate a divergent canonical Wnt pathway involving Gsk $3 \beta$, which regulated the presynaptic microtubule cytoskeleton (Ataman et al. 2008; Miech et al. 2008). On the other hand, activation of postsynaptic muscle DFz2 receptors turned on a novel Wg-signaling pathway, the so-called Frizzled nuclear import pathway (FNI) (Fig. 1E), which was required for building the postsynaptic apparatus (Mathew et al. 2005; Ataman et al. 2006, 2008; Mosca and Schwarz 2010; Speese et al. 2012).

Using antibodies specifically recognizing the carboxyl terminus and amino terminus of DFz2, it was shown that in postsynaptic muscles, the DFz2 receptor was endocytosed and trafficked to the periphery of the muscle nucleus, likely in an 
endocytic vesicle, where its cytoplasmic carboxy-terminal fragment was cleaved. Whereas the 8-kDa carboxy-terminal fragment of DFz2 (DFz2C) was imported into the nucleus, the amino-terminal fragment remained at the nuclear periphery. Within the nucleus, DFz2C formed submicrometer-sized foci (Mathew et al. 2005). Overexpressing Wg in motor neurons, which increased the levels of secreted $\mathrm{Wg}$ around synaptic boutons, led to an increase in the number of nuclear DFz2C foci in the muscles, and decreasing Wg secretion in $w g$ mutants or interfering with DFz2 signaling in muscles led to the opposite effect (Mathew et al. 2005).

The cleavage of DFz2 was found to be required for Wg signaling in the muscle. Expression of a DFz2 transgene in the muscle, carrying a mutation that eliminated the cleavage site, in a $d f z 2$ mutant background did not rescue the reduced bouton number observed in $d f z 2 \mathrm{mu}-$ tants (Mathew et al. 2005). Importantly, attempts to circumvent the nuclear import pathway by expressing a tagged DFz2C fragment failed, because this did not rescue the reduced bouton number in $d f z 2$ mutants (Mathew et al. 2005; but see Mosca and Schwarz 2010). These findings led the investigators to suggest that an interaction between the full-length $\mathrm{DFz} 2$ and Wg was likely required to make DFz2C competent for nuclear import and signaling.

The journey of DFz2 from the plasma membrane to the nucleus involved a direct interaction between the carboxyl terminus of DFz2C, which contains a PDZ binding sequence, and the 7 PDZ domain protein dGRIP (glutamate receptor interacting protein) (Ataman et al. 2006). In the vertebrate nervous system, GRIP mediates the synaptic trafficking and scaffolding of several proteins, including AMPA (Dong et al. 1997) and EphB (Hoogenraad et al. 2005) receptors. In Drosophila, mutations in dgrip or selective postsynaptic reduction in dGRIP levels led to phenotypes that highly resembled mutations in Wnt signaling (Ataman et al. 2006). These included a drastically reduced number of nuclear DFz2C foci, a reduced number of synaptic boutons, and an increase in the number of ghost boutons. Analysis of the trafficking of DFz2 receptors by using an antibody against the extracellular amino terminus of DFz2, which binds to the receptor in vivo, allowed the researchers to follow receptor trafficking through pulse-chase experiments. In wild-type larvae, DFz2 receptors localized at the postsynaptic region traffic toward the nucleus over time. However, when dGRIP levels were reduced, DFz2 accumulated at the postsynaptic region and failed to be transported toward the nucleus (Ataman et al. 2006). These observations suggested that dGRIP was required to transport DFz2C from the muscle plasma membrane to the nucleus.

Further insight into the FNI pathway was provided by Mosca and Schwarz (2010), who showed that the nuclear import of DFz2C requires the nucleoporin-associated proteins Importin- $\beta 11$ (Imp- $\beta 11)$ and Importin- $\alpha 2$ (Imp$\alpha 2)$. In the absence of either of these two importins, synapses displayed phenotypes that resembled the alterations found at NMJs of $w g, d f z 2$, and dgrip mutants, that is, a reduced number of synaptic boutons, an excessive number of ghost boutons, and a reduced thickness of the subsynaptic reticulum (SSR) (Mosca and Schwarz 2010). These results indicate that importins and therefore nuclear entry of DFz2C fragments through the canonical nuclear import pathway are key players in the FNI Wnt pathway.

More recently, Speese et al. (2012) have begun to unravel the function of DFz2C foci within the nucleus. The foci are composed of large ribonucleoprotein (RNP) particles bearing synaptic protein transcripts. These granules localize to the space between the inner and outer nuclear membrane and require Lamin C, a nuclear protein linked to muscular dystrophies (Worman and Bonne 2007). lam C mutations mimicked NMJ phenotypes of mutations interfering with the FNI pathway. Notably, it was shown that the granules exit the nucleus via a budding mechanism akin to the nuclear egress of Herpes-type viruses (Mettenleiter et al. 2006), a process previously thought to be exclusive for these viruses. Like HSV nuclear egress, this process required $\mathrm{PKC}$, which is known to disrupt the lamin through phosphorylation. It was suggested that nuclear envelope budding is an endogenous nuclear export mechanism for large 
RNPs (Speese et al. 2012). Interestingly, the nuclear DFz2C foci contained transcripts encoding synaptic proteins, such as Par6 and CaMKII, and some of the transcripts were also found at the NMJ. These observations suggested that the large RNPs were required for local translation of the postsynaptic apparatus during new synaptic bouton formation (Speese et al. 2012). Although the exact function of DFz2C fragments within the large RNP granules is not known, the authors speculate that the PDZ binding domain of DFz2C may serve as a zipcode to properly target large RNPs to synaptic sites. Several PDZ-containing scaffolding proteins are localized at postsynaptic sites and are required for synaptic development at the NMJ (Lahey et al. 1994; Thomas et al. 1997; Zito et al. 1997; Mathew et al. 2002). Furthermore, proteins containing PDZ-binding motifs are known to be targeted to postsynaptic sites (Zito et al. 1999). Although the generality of the FNI signaling pathway for other systems and tissues is presently unknown, nuclear DFz2C foci are also observed in Schneider-2 cells and at Drosophila larval salivary glands (Speese et al. 2012), where the nuclear envelope granules were first observed along with epithelial cells of the midgut (Gay 1956; Hochstrasser and Sedat 1987). In addition, these foci are observed in peripheral glial cells in the larva (SD Speese and V Budnik, unpubl.). Notably, granules accumulating between the outer and inner nuclear membrane resembling the DFz2-decorated large RNP granules have been observed in diverse contexts, from plants (Dickinson 1971) to mammals, where they are particularly prevalent at early embryonic stages (Hadek and Swift 1962; Szollosi 1965). Indeed, that such granules might reflect an alternate mode of nucleocytoplasmic export has been previously proposed (Gay 1956; Szollosi and Szollosi 1988), but it had not been experimentally validated until now. However, whether these granules are also associated with Frizzled receptor fragments is currently unknown.

As discussed above, $\mathrm{Wg}$ also turns on a presynaptic signaling pathway with resemblance to the canonical Wnt signaling pathway (Ataman et al. 2008; Miech et al. 2008). Several components of the canonical Wnt signaling pathway can be detected in presynaptic boutons (Packard et al. 2002; Miech et al. 2008), including Dishevelled (Dvl), Gsk3ß/Shaggy, DFz2 and its coreceptor Arrow/Lrp5/6, but not Armadillo/ $\beta$-catenin (Miech et al. 2008). Mutations in arrow/Lrp5/6, a receptor thought to be involved in canonical Wnt signaling ( $\mathrm{He}$ et al. 2004), showed phenotypes similar to those observed in $w g$ mutants such as reduced bouton number, increase in large ( $>5 \mu \mathrm{m})$, irregularly shaped boutons, and decrease in the number of boutons with presynaptic Futsch loops (Miech et al. 2008). However, the presence of ghost boutons was not examined in those studies. All of these phenotypes were rescued by the presynaptic expression of Arrow. Notably, expressing an arrow transgene in muscles of arr mutants also rescued the reduced bouton number while not rescuing the presynaptic microtubule phenotypes. In addition, Arrow overexpression in neurons resulted in an increase in the number of bouton and satellite boutons, similarly to what was shown for presynaptic Wg overexpression (Packard et al. 2002; Miech et al. 2008). Subsequent experiments indicated that $\mathrm{Wg}$ binding to presynaptic Arrow leads to the activation of a divergent canonical pathway. Indeed, overexpression of a dominant negative Dvl in neurons, but not in muscle, led to the prototypical $w g$ mutant phenotypes, whereas overexpression of dominant negative Gsk $3 \beta / \mathrm{Sgg}$, as expected, resulted in the opposite phenotype, mimicking $\mathrm{Wg}$ overexpression (Franco et al. 2004; Miech et al. 2008). No phenotypic changes were observed upon dominant negative TCF/ pangolin or Armadillo/ $\beta$-catenin overexpression in neurons (Miech et al. 2008), suggesting that the dominant negative Dvl and Gsk3 $\beta$ overexpression phenotypes did not result from interfering with canonical Wnt signaling. Thus, by activating alternative signaling pathways, a single Wnt simultaneously coordinates presynaptic and postsynaptic development.

An important avenue of inquiry examined the involvement of Wnt signaling during synaptic plasticity. Ataman et al. (2008) showed that larval NMJs respond to repeated or patterned stimulation administered via high-potassium depolarization, motor nerve stimulation, 
or blue light stimulation of channelrhodopsin2 (Nagel et al. 2002) expressing motor neurons, by extending new "synaptopods," dynamic filopodia-like structures that are observed, albeit at lower frequency, in unstimulated animals (Ataman et al. 2008). In addition, NMJs respond to these stimuli by forming new ghost boutons. Analysis by time-lapse microscopy revealed that a subset of these ghost boutons could subsequently mature by acquiring active-zone and postsynaptic proteins, suggesting that ghost boutons are an undifferentiated state of mature boutons. In addition to the above morphological changes, the frequency of spontaneous miniature synaptic potentials (mEJPs) was potentiated by these stimulation paradigms. The above changes required at least five stimulation bouts separated by a resting period, and intact transcriptional and translational machinery. Most importantly, Wg signaling was necessary for these changes downstream from motor neuron stimulation, because removing just one copy of the $w g$ gene was sufficient to eliminate the structural and functional changes elicited by patterned stimulation. Furthermore, neuronal overexpression of Wg, which increased Wg secretion by synaptic boutons, reduced the number of cycles required to initiate the structural and functional changes (Ataman et al. 2008). Thus, these studies show that Wg not only plays a developmental role during NMJ expansion, but is also involved in acute, activity-dependent remodeling of the NMJ.

Another interesting aspect of the $\mathrm{Wg}$ signaling pathway uncovered recently is the observation that $\mathrm{Wg}$ secretion from motor neuron axonal terminals requires the evolutionarily conserved segment polarity protein Evenness interrupted (Evi)/Wntless (Wls)/Sprinter (Spr) (Banziger et al. 2006; Bartscherer et al. 2006; Goodman et al. 2006). Similarly to observations in embryos, cell culture, and developing wing discs (Banziger et al. 2006; Bartscherer et al. 2006; Goodman et al. 2006), Wg release from motor neuron terminals at the NMJ requires Evi (Fig. 4A) (Korkut et al. 2009). Mutations in Evi or specific Evi down-regulation in motor neurons led to drastic reduction in $\mathrm{Wg}$ release from synaptic boutons, and phenocopied the $w g^{t s}$ phenotypes. Because Evi, a multipass transmembrane protein, was shown to cross the synapse with Wg (Korkut et al. 2009), it was suggested that Evi-containing microvesicles, possibly exosomes, play a role in $\mathrm{Wg}$ transfer at the synapse (Korkut et al. 2009). This mechanism addressed a long-lasting problem in the transmission of Wnt signals, this being in the formation of gradients during pattern formation in the embryo or in the traffic of Wnts from presynaptic sites to relatively distant sites at the subsynaptic reticulum, a complex system of muscle-derived postsynaptic membranes, where DFz2 receptors are localized. Although the primary amino acid sequence of Wnts predicts a hydrophilic molecule, Wnts are actually hydrophobic in nature, because of posttranslational lipid modifications (Willert et al. 2003; Takada et al. 2006). Thus, Wnts are not readily diffusible in the extracellular space. Several mechanisms have been documented to be involved in the diffusion of Wnt signals, including the association of Wnt proteins with lipoprotein particles (Panakova et al. 2005), the transmission of argosomes (Greco et al. 2001), cytonemes (Ramirez-Weber and Kornberg 1999), and, very recently, Secreted Wg-interacting molecule (Swim), a member of the Lipocalin family that is suggested to maintain $\mathrm{Wg}$ in a soluble form for long-range signaling (Mulligan et al. 2012). The studies at the NMJ suggest yet another mechanism, the shuttling of Wnts associated with Evi, which is released in vesicles (Fig. 4A). Most recently, analysis of the Evi vesicles showed that they indeed correspond to exosomes (K Koles and V Budnik, unpubl.). Exosomes are released by the fusion of multivesicular bodies with the plasma membrane, thus releasing their vesicular content. Our initial studies indicate that Evi-exosome release from presynaptic terminals requires Rab11, Myosin 5, and Syntaxin-1A, suggesting that exosome release is an integral component of the synaptic bouton release machinery.

Most recently, Wg signaling has been implicated in negatively regulating homeostatic compensation (Marie et al. 2010). Neurotransmitter release and postsynaptic muscle depolarization are tightly coupled processes, and their 
K. Koles and V. Budnik
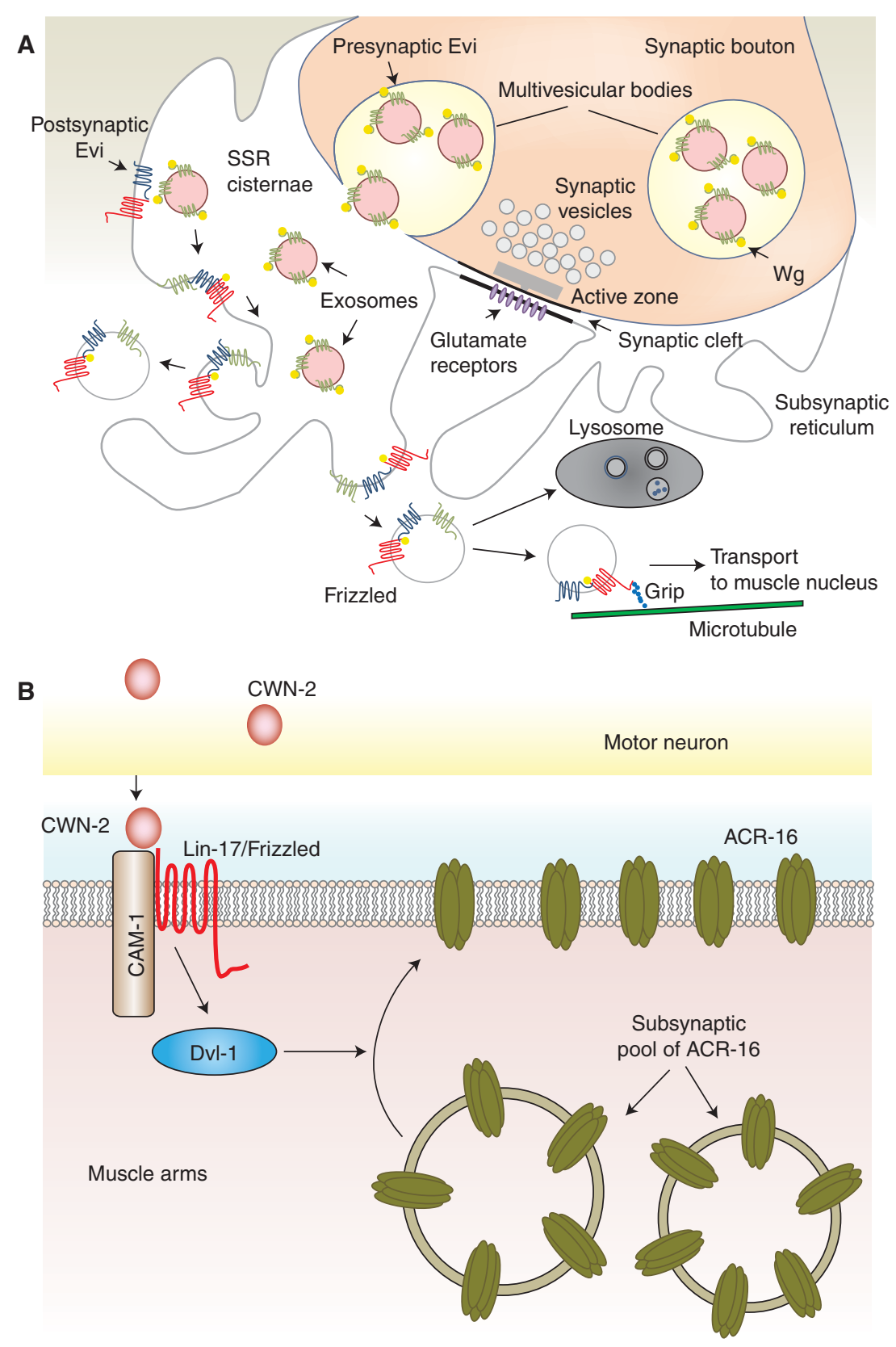

Figure 4. Evi-mediated synaptic release of Drosophila Wg and regulation of ACR-16 receptor abundance in postsynaptic muscle membranes by CWN-2 in C. elegans. (A) Schematic representation of Evi-mediated Wg release at Drosophila larval NMJs. Wg carried by Evi-exosomes is sorted into multivesicular bodies in synaptic terminals that fuse with the synaptic membrane, releasing their content to the cisternae of underlying subsynaptic reticulum. Potential fates of postsynaptic exosomes are shown, such as fusion with the postsynaptic membrane and subsequent endocytosis. The endocytosed $\mathrm{DFz} 2 / \mathrm{Wg} /$ Evi-containing vesicles can be either sorted and targeted to lysosomes or, via DFz2 binding to Grip, transported near the muscle nucleus (also see Fig. 1E). (B) In C. elegans, motor neurons release CWN-2, which binds to the heteromeric CAM-1/Lin-17 receptor and activates Dishevelled-1. Activated Dvl-1, in turn, leads to the mobilization and membrane delivery of subsynaptic ACR-16 receptor pools. 
coordination is required to maintain synaptic efficacy. The process of synaptic homeostasis involves the presynaptic (increase in neurotransmitter release) or postsynaptic (abundance of glutamate receptors) compensatory adjustment to changes in postsynaptic or presynaptic parameters, resulting in the restoration of wildtype synaptic efficacy. Synaptic homeostasis is thought to occur in two phases, an induction phase that is transcription and protein synthesis independent, and a maintenance phase that requires transcription and the presynaptic BMPsignaling pathway (Goold and Davis 2007). Marie et al. (2010) have recently shown that Goosberry $(G s b)$ is required for the maintenance phase of this homeostatic compensation process. Using the GluRIIA ${ }^{\text {sp16 }}$-null mutant background (Petersen et al. 1997), which leads to a compensatory increase in presynaptic neurotransmitter release due to a decrease in the amplitude of spontaneous mEPSPs, the investigators discovered that this compensation was significantly reduced in heterozygous $g s b^{01155}$ mutants (Marie et al. 2010). Interestingly, Gsb also functions early during embryonic development to inhibit Wg signaling in the Wg-secreting cell (Duman-Scheel et al. 1997). Indeed, when the investigators examined the possibility of whether Gsb may function in homeostatic compensation in motor neurons by inhibiting presynaptic Wg signaling, they found that replacing one copy of the wild-type $w g$ gene with a temperature-sensitive $w g^{t s}$ allele in the $g s b^{01155} /+$ GluRIIA ${ }^{\text {sp16 }}$ background restored homeostatic compensation (Marie et al. 2010). Therefore, in addition to its other structural and functional roles at the NMJ, these results raise the interesting possibility that $\mathrm{Wg}$, along with BMP signaling, regulates synaptic homeostasis (Marie et al. 2010).

In addition to Wingless, two additional Wnt family members-Wnt5, its postsynaptic receptor Derailed (Drl) (Liebl et al. 2008), and Wnt2 (Liebl et al. 2010)—were also shown to regulate NMJ development. Mutations in Wnt5 led to structural as well as functional defects at the NMJ. Bouton numbers and NMJ areas were significantly decreased in wnt5 mutants, and the number and density of active zones, as assessed by Bruchpilot (Brp) immunolabeling, was also significantly lower. Interestingly, only neuronal Wnt5 expression was able to rescue bouton numbers to wild type, but either neuronal or muscle-specific rescue restored the number and density of active zones, suggesting a potential retrograde function for Wnt5 in regulating active-zone formation. Electrophysiological examination of wnt5 mutant synapses revealed a $40 \%$ decrease in evoked excitatory junctional currents (EJCs) and a similar decrease in the frequency of mEJCs (Liebl et al. 2008). Because the amplitude of mEJCs (which reflects postsynaptic glutamate receptor function) was not affected in wnt5 mutants, these data point toward the presynaptic function of Wnt5. Earlier studies have shown that Wnt5 can bind Derailed (Drl) (Yoshikawa et al. 2003). Indeed, drl mutant NMJs manifest similar structural defects to wnt5 mutants, such as a significant decrease in bouton number (Liebl et al. 2008). This phenotype could be rescued by postsynaptic expression of Drl. However, there were also differences in the phenotypes of $d r l$ and wnt5 mutant larvae. $d r l$ mutations, unlike $w n t 5$ mutations, did not result in a decrease in active-zone density, nor in functional changes in synaptic transmission, suggesting that some aspects of Wnt5 function are Drl independent. It is interesting to note, however, that presynaptic expression of Wnt5 in the wild-type background led to a significant increase in bouton number, and that this increase was dependent on Drl, because in the $d r l$ mutant background no change in bouton number was observed upon neuronal Wnt5 overexpression. In summary, Wnt5 is posed to play a complex structural and functional role at the larval NMJ, in part by signaling via the Drl receptor, while also showing Drl-independent effects.

Subsequently, the same researchers have shown that Drosophila Wnt2, the ortholog of mammalian $W n t 7 b$, is required for proper NMJ development and for the maintenance of proper Brp density and intensity at synapses (Liebl et al. 2010). In the absence of Wnt2, presynaptic arbors branch more frequently, although the number of boutons is unchanged, indicating that unlike other Wnts, Wnt2 negatively regulates 
NMJ branching. The total number of Brp puncta did not change in Wnt2 mutants. However, the density of Brp puncta decreased significantly, as expected from the increased NMJ arbor size in these mutants. A combination of rescue experiments with Wnt2 overexpression and tissue-specific knockdown of Wnt2 suggests that it functions in the muscle, most likely in a retrograde manner to negatively regulate presynaptic growth. In addition to the structural phenotypes, Wnt2 mutants showed a decrease in the mean intensity of Synaptobrevin (Syb) and Brp immunoreactivity. In agreement with these observations, the amplitude of evoked excitatory junctional potentials was also reduced, whereas the frequency and amplitude of spontaneous vesicle release were unaffected. It is as yet unclear what receptor Wnt2 signals through at the NMJ. Previous studies implicated Fz, DFz2, and Fz3 as potential receptors for Wnt2 (Wu and Nusse 2002), but genetic studies did not affirm these possibilities at the larval NMJ (Liebl et al. 2010).

\section{THE ROLE OF WNTs AT C. elegans NMJs}

The muscles of C. elegans are innervated by excitatory cholinergic or inhibitory GABAergic neurons. Unlike Drosophila or vertebrate NMJs, muscles extend "muscle arms" toward the nerve cord to form en passant synapses (Dixon and Roy 2005). Two types of acetylcholine receptors (AChRs) have been identified in C. elegans, the N-type, likely a homomer of ACR-16 subunits (Francis et al. 2005) and activated by nicotine, and the L-type channels, which are heteropentamers and sensitive to levamisole. Two distinct mechanisms have evolved to localize these two types of receptors. N-type AChRs require CAM1, a MuSK-related orphan receptor tyrosine kinase (Francis et al. 2005), and N-type AChRs require an extracellular scaffold in the synaptic cleft, composed of secreted Lev-9 (Gendrel et al. 2009), the extracellular domain of Lev-10 (Gally et al. 2004), and a small, secreted single immunoglobulin containing OIG-4 (Rapti et al. 2011).

Although in vertebrates and Drosophila, initial discoveries revealed pro-synaptogenic functions for Wnts (even though subsequent exper- iments identified negatively acting Wnt signals as well), the first C. elegans Wnt signaling pathway involved in regulating synapse formation served to restrict the position of synapses on axons. For a while these findings led to the notion that Wnts were inhibitory in C. elegans; however, some of the latest discoveries seem to dispel this notion (see below).

The first Wnt discovered to function in $C$. elegans neuromuscular junction formation was Lin-44 (Klassen and Shen 2007). Lin-44/Wnt is secreted from four hypodermal cells during embryonic and larval development. In lin-44/wnt mutants, ectopic synapses are formed, indicating that lin-44/wnt inhibits synapse formation. Lin-44/Wnt functions in DA9 motor neurons, where it recruits the Wnt receptor Lin-17/Frizzled to a subdomain of the DA9 axon via binding to the cysteine-rich domain (CRD) of Lin17/Frizzled. Lin-44/Wnt cooperates with another C. elegans Wnt, EGL-20/Wnt, and by binding to and signaling through Lin-17/Frizzled, it prevents synapse formation at this region of the DA9 axon (Klassen and Shen 2007). Interestingly, except for Dvl, none of the known canonical, planar cell polarity, or calcium-dependent Wnt signaling pathway effectors were found to be involved in this process, suggesting that novel effectors mediate the local inhibition of synaptogenesis on DA9 motor neuron axons.

An additional aspect of Wnt signaling regulation at the C. elegans NMJ was revealed by the findings of Babu et al. (2011). In an RNAi screen for cell surface Ig-domain-containing (IgSF) proteins that are involved in modulating sensitivity to aldicarb (a cholinesterase inhibitor), Babu and colleagues identified RIG-3, a GPI-anchored IgSF-domain protein. Decreased levels of this protein, which is normally expressed in cholinergic neurons, led to heightened sensitivity to aldicarb. When the investigators examined the underlying mechanisms for this increased sensitivity, they found that in the absence of RIG-3, the delivery of ACR16 (the homomer-forming subunit of nicotinic AChRs) from muscle mobile stores to the muscle membrane was significantly increased following aldicarb treatment. Furthermore, this increase was the result of increased levels of 
CAM-1, which is an unconventional Wnt receptor of the Ror-type receptor tyrosine kinase family (Green et al. 2008) involved in ACR-16 delivery to synaptic sites (Francis et al. 2005). Interestingly, CAM-1 binds Wnt ligands, and mutations that reduce secreted Wnt levels, such as mig-14, led to the elimination of aldicarb-induced hypersensitivity in rig-3, mig-14 double mutants, indicating that CAM-1 was mediating this phenotype in a Wnt-dependent manner. These data show that RIG-3, a presynaptic molecule, negatively regulates CAM-1mediated Wnt signaling at ACR-16-containing synapses following aldicarb treatment and thus may play a role in stabilizing synapses and synaptic circuits.

As mentioned above, the first discovery of C. elegans Wnt signaling in NMJ formation revealed the negative regulation of synapse formation, suggesting that Wnts may be inhibitory in C. elegans. However, a new study from Jensen et al. (2012) seems to dispel this notion. In a series of elegant and groundbreaking studies, the researchers showed that neuronally released CWN-2 (but not CWN-1 or EGL-20), by binding to the CAM-1/Lin-17 heteromeric receptor (but not those containing MIG-1 or CFZ-2), resulted in the increased postsynaptic muscle membrane delivery of ARC-16 (Fig. 4B). This signaling required ongoing $\mathrm{CWN}-2$ release, because transient CWN-2 pulses led to only transient increases in postsynaptic ACR-16. For the first time in $C$. elegans, the investigators also showed that this Wnt signaling pathway was activity dependent. Channelrhodopsin 2 stimulation of neurons led to an increased translocation of ACR-16 to the muscle membrane and a corresponding increase in ACR-16-mediated current, and these effects required the neuronal expression of CWN-2. In summary, an ongoing, activity-dependent CWN-2 release and signaling through CAM-1/Lin-17 receptors is required for activity-dependent synaptic plasticity and the maintenance of proper synaptic transmission in adult C. elegans neuromuscular junctions. These observations also point out the similarities of Wnt function at the NMJ across species. The activity-dependent release and anterograde function of CWN-2 are strik- ingly similar to what has been described for $\mathrm{Wg}$ at Drosophila larval NMJs (Ataman et al. 2008). In a broader context, these new results highlight that Wnts do not only function during development, but are also required throughout the life span of organisms for proper synaptic functioning.

\section{CONCLUDING REMARKS}

In the last decade, we have witnessed a large number of new discoveries regarding the function of Wnt signaling at neuromuscular synapse formation and function. From these findings, it is apparent that Wnts are intricately involved in almost every aspect of NMJ development, maintenance, and function, including activitydependent plasticity. They can play both essential and modulatory roles and promote or inhibit synapse formation. As surmised by Speese and Budnik (2007) and van Amerongen and Nusse (2009), the likely scenario of Wnt action is that of a parallel, combinatorial network of signals emanating from the neuron, muscle, and surrounding non-neuronal cells that work in anterograde, retrograde, and autocrine manner to effect and coordinate the developmental and synaptic plasticity-induced processes.

One of the key challenges of the Wnt signaling field will be to reconcile data from in vivo and in vitro experiments. For example, Dvl1 was identified via its MuSK interaction and was shown to be required for Agrin-induced AChR clustering, yet the Dvll mutant mouse phenotypes are surprisingly mild compared with the Dvl1 knockdown in $\mathrm{C} 2 \mathrm{C} 12$ cell cultures (Luo et al. 2002). Furthermore, in muscle-specific $\beta$ catenin $^{-/-}$knockout muscle cultures, Agrinmediated AChR clustering was not affected ( $\mathrm{Li}$ et al. 2008), unlike in the $\mathrm{C} 2 \mathrm{C} 12$ cultured cell line, where $\beta$-catenin levels were reduced via shRNA treatment (Zhang et al. 2007; Wang et al. 2008). These data highlight the difficulties involved in translating the cell culture findings to in vivo situations in a living/developing organism. These data illustrate that multiple pathways may converge at the level of $\beta$-catenin and that the preceding developmental history of the cell could lead to diverse compensatory 
mechanisms or adaptations that may lead to conflicting results if these factors are not controlled for.

Among the exciting future challenges will be the identification of retrograde signaling mechanisms that were revealed through examining the muscle specific $\beta$-catenin ${ }^{-/-}$NMJs (Li et al. 2008). Likewise, because many aspects of Wnt signaling are conserved across species, it will be exciting to test whether the continuous, ongoing requirement for C. elegans Wnt, CWN2 , in synaptic plasticity (Jensen et al. 2012) is also at play in other model organisms, such as the fly, zebrafish, or other vertebrates. Furthermore, the contribution to NMJ development and function of terminal Schwann cells in vertebrates (Feng and Ko 2008; Sugiura and Lin 2011) is poised to lead to novel insights.

In addition, future research is likely to lead to an integrated model of multiple Wnt signaling pathways (van Amerongen and Nusse 2009) that are acting simultaneously and synergistically from multiple tissue sources (nerve, muscle, somites, glia) to sculpt the synapse. Current efforts naturally focus on delineating single, rather than multiple, linear signaling pathway effects (e.g., as described above, Wnt1, Wnt5, and Wnt2 are all involved in Drosophila larval NMJ development); however, their integration into a dynamic, spatio-temporal map of signaling events will transform our understanding of NMJ development and function. Given how far the field has come in the last few decades and the continuous technical advances allowing more nuanced experiments to be performed, future developments in the field of Wnt signaling at the neuromuscular synapse are bound to be exciting.

\section{ACKNOWLEDGMENTS}

We thank Dr. Cassandra Brewer for critical review of the manuscript. V.B. is supported by NIH grants RO1 MH070000 and R01 NS063228.

\section{REFERENCES}

Anderson MJ, Cohen MW. 1977. Nerve-induced and spontaneous redistribution of acetylcholine receptors on cultured muscle cells. J Physiol 268: 757-773.
Aoki K, Taketo MM. 2007. Adenomatous polyposis coli (APC): A multi-functional tumor suppressor gene. $J$ Cell Sci 120: 3327-3335.

Ataman B, Ashley J, Gorczyca D, Gorczyca M, Mathew D, Wichmann C, Sigrist SJ, Budnik V. 2006. Nuclear trafficking of Drosophila Frizzled-2 during synapse development requires the PDZ protein dGRIP. Proc Natl Acad Sci 103: 7841-7846.

Ataman B, Ashley J, Gorczyca M, Ramachandran P, Fouquet W, Sigrist SJ, Budnik V. 2008. Rapid activity-dependent modifications in synaptic structure and function require bidirectional Wnt signaling. Neuron 57: 705-718.

Babu K, Hu Z, Chien SC, Garriga G, Kaplan JM. 2011. The immunoglobulin super family protein RIG-3 prevents synaptic potentiation and regulates Wnt signaling. Neuron 71: $103-116$.

Banziger C, Soldini D, Schutt C, Zipperlen P, Hausmann G, Basler K. 2006. Wntless, a conserved membrane protein dedicated to the secretion of Wnt proteins from signaling cells. Cell 125: 509-522.

Barrow JR, Thomas KR, Boussadia-Zahui O, Moore R, Kemler R, Capecchi MR, McMahon AP. 2003. Ectodermal Wnt $3 / \beta$-catenin signaling is required for the establishment and maintenance of the apical ectodermal ridge. Genes Dev 17: 394-409.

Bartscherer K, Pelte N, Ingelfinger D, Boutros M. 2006. Secretion of Wnt ligands requires Evi, a conserved transmembrane protein. Cell 125: 523-533.

Bergamin E, Hallock PT, Burden SJ, Hubbard SR. 2010. The cytoplasmic adaptor protein Dok7 activates the receptor tyrosine kinase MuSK via dimerization. Mol Cell 39: $100-109$.

Budnik V, Zhong Y, Wu CF. 1990. Morphological plasticity of motor axons in Drosophila mutants with altered excitability. J Neurosci 10: 3754-3768.

Burden SJ. 2011. SnapShot: Neuromuscular junction. Cell 144: 826-826.el.

Cadigan KM, Peifer M. 2012. Wnt signaling from development to disease: Insights from model systems. Cold Spring Harb Perspect Biol doi: 10.1101.cshperspect. a002881.

Caricasole A, Bakker A, Copani A, Nicoletti F, Gaviraghi G, Terstappen GC. 2005. Two sides of the same coin: Wnt signaling in neurodegeneration and neuro-oncology. Biosci Rep 25: 309-327.

Ciani L, Krylova O, Smalley MJ, Dale TC, Salinas PC. 2004. A divergent canonical WNT-signaling pathway regulates microtubule dynamics: Dishevelled signals locally to stabilize microtubules. J Cell Biol 164: 243-253.

DeChiara TM, Bowen DC, Valenzuela DM, Simmons MV, Poueymirou WT, Thomas S, Kinetz E, Compton DL, Rojas E, Park JS, et al. 1996. The receptor tyrosine kinase $\mathrm{MuSK}$ is required for neuromuscular junction formation in vivo. Cell 85: 501-512.

De Ferrari GV, Inestrosa NC. 2000. Wnt signaling function in Alzheimer's disease. Brain Res Brain Res Rev 33: 1-12.

Dickinson HG. 1971. Nucleo-cytoplasmic interaction following meiosis in the young microspores of Lilium longiflorum; events at the nuclear envelope. Grana 11: 117127. 
Dixon SJ, Roy PJ. 2005. Muscle arm development in Caenorhabditis elegans. Development 132: 3079-3092.

Dong H, O’Brien RJ, Fung ET, Lanahan AA, Worley PF, Huganir RL. 1997. GRIP: A synaptic PDZ domain-containing protein that interacts with AMPA receptors. $\mathrm{Na}$ ture 386: 279-284.

Duman-Scheel M, Li X, Orlov I, Noll M, Patel NH. 1997. Genetic separation of the neural and cuticular patterning functions of gooseberry. Development 124: 2855-2865.

Farias GG, Valles AS, Colombres M, Godoy JA, Toledo EM, Lukas RJ, Barrantes FJ, Inestrosa NC. 2007. Wnt-7a induces presynaptic colocalization of $\alpha 7$-nicotinic acetylcholine receptors and adenomatous polyposis coli in hippocampal neurons. J Neurosci 27: 5313-5325.

Feng Z, Ko CP. 2008. The role of glial cells in the formation and maintenance of the neuromuscular junction. Ann NYAcad Sci 1132: 19-28.

Flanagan-Steet H, Fox MA, Meyer D, Sanes JR. 2005. Neuromuscular synapses can form in vivo by incorporation of initially aneural postsynaptic specializations. Development 132: 4471-4481.

Fradkin LG, Dura JM, Noordermeer JN. 2010. Ryks: New partners for Wnts in the developing and regenerating nervous system. Trends Neurosci 33: 84-92.

Frail DE, McLaughlin LL, Mudd J, Merlie JP. 1988. Identification of the mouse muscle 43,000-dalton acetylcholine receptor-associated protein (RAPsyn) by cDNA cloning. J Biol Chem 263: 15602-15607.

Francis MM, Evans SP, Jensen M, Madsen DM, Mancuso J, Norman KR, Maricq AV. 2005. The Ror receptor tyrosine kinase CAM-1 is required for ACR-16-mediated synaptic transmission at the C. elegans neuromuscular junction. Neuron 46: 581-594.

Franco B, Bogdanik L, Bobinnec Y, Debec A, Bockaert J, Parmentier ML, Grau Y. 2004. Shaggy, the homolog of glycogen synthase kinase 3, controls neuromuscular junction growth in Drosophila. J Neurosci 24: 6573-6577.

Gally C, Eimer S, Richmond JE, Bessereau JL. 2004. A transmembrane protein required for acetylcholine receptor clustering in Caenorhabditis elegans. Nature 431: 578 582.

Gay H. 1956. Nucleocytoplasmic relations in Drosophila. Cold Spring Harb Symp Quant Biol 21: 257-269.

Gendrel M, Rapti G, Richmond JE, Bessereau JL. 2009. A secreted complement-control-related protein ensures acetylcholine receptor clustering. Nature 461: 992-996.

Gesemann M, Denzer AJ, Ruegg MA. 1995. Acetylcholine receptor-aggregating activity of agrin isoforms and mapping of the active site. J Cell Biol 128: 625-636.

Glass DJ, Bowen DC, Stitt TN, Radziejewski C, Bruno J, Ryan TE, Gies DR, Shah S, Mattsson K, Burden SJ, et al. 1996. Agrin acts via a MuSK receptor complex. Cell 85: 513-523.

Gogel S, Wakefield S, Tear G, Klambt C, Gordon-Weeks PR. 2006. The Drosophila microtubule associated protein Futsch is phosphorylated by Shaggy/Zeste-white 3 at an homologous GSK3 $\beta$ phosphorylation site in MAP1B. Mol Cell Neurosci 33: 188-199.

Gomez AM, Burden SJ. 2011. The extracellular region of Lrp4 is sufficient to mediate neuromuscular synapse formation. Dev Dyn 240: 2626-2633.
Goodman RM, Thombre S, Firtina Z, Gray D, Betts D, Roebuck J, Spana EP, Selva EM. 2006. Sprinter: A novel transmembrane protein required for $\mathrm{Wg}$ secretion and signaling. Development 133: 4901-4911.

Goold CP, Davis GW. 2007. The BMP ligand Gbb gates the expression of synaptic homeostasis independent of synaptic growth control. Neuron 56: 109-123.

Gorczyca M, Augart C, Budnik V. 1993. Insulin-like receptor and insulin-like peptide are localized at neuromuscular junctions in Drosophila. J Neurosci 13: 3692-3704.

Greco V, Hannus M, Eaton S. 2001. Argosomes: A potential vehicle for the spread of morphogens through epithelia. Cell 106: 633-645.

Green JL, Kuntz SG, Sternberg PW. 2008. Ror receptor tyrosine kinases: Orphans no more. Trends Cell Biol 18: 536-544.

Hadek R, Swift H. 1962. Nuclear extrusion and intracisternal inclusions in the rabbit blastocyst. J Cell Biol 13: $445-451$.

Hall AC, Lucas FR, Salinas PC. 2000. Axonal remodeling and synaptic differentiation in the cerebellum is regulated by WNT-7a signaling. Cell 100: 525-535.

Hallock PT, Xu CF, Park TJ, Neubert TA, Curran T, Burden SJ. 2010. Dok-7 regulates neuromuscular synapse formation by recruiting Crk and Crk-L. Genes Dev 24: 24512461.

He X. 2012. Wnt receptors and signaling mechanisms. Cold Spring Harb Perspect Biol doi: 10.1101/cshperspect.a007880.

He X, Semenov M, Tamai K, Zeng X. 2004. LDL receptorrelated proteins 5 and 6 in Wnt $/ \beta$-catenin signaling: Arrows point the way. Development 131: 1663-1677.

Henriquez JP, Webb A, Bence M, Bildsoe H, Sahores M, Hughes SM, Salinas PC. 2008. Wnt signaling promotes AChR aggregation at the neuromuscular synapse in collaboration with agrin. Proc Natl Acad Sci 105: $18812-$ 18817.

Hochstrasser M, Sedat JW. 1987. Three-dimensional organization of Drosophila melanogaster interphase nuclei. II. Chromosome spatial organization and gene regulation. Cell Biol 104: 1471-1483.

Hoogenraad CC, Milstein AD, Ethell IM, Henkemeyer M, Sheng M. 2005. GRIP1 controls dendrite morphogenesis by regulating EphB receptor trafficking. Nat Neurosci 8: 906-915.

Inoue A, Setoguchi K, Matsubara Y, Okada K, Sato N, Iwakura Y, Higuchi O, Yamanashi Y. 2009. Dok-7 activates the muscle receptor kinase MuSK and shapes synapse formation. Sci Signal 2: ra7. doi: 10.1126/scisignal. 2000113.

Jennings CG, Dyer SM, Burden SJ. 1993. Muscle-specific trk-related receptor with a kringle domain defines a distinct class of receptor tyrosine kinases. Proc Natl Acad Sci 90: 2895-2899.

Jensen M, Hoerndli FJ, Brockie PJ, Wang R, Johnson E, Maxfield D, Francis MM, Madsen DM, Maricq AV. 2012. Wnt signaling regulates acetylcholine receptor translocation and synaptic plasticity in the adult nervous system. Cell (in press).

Jing L, Lefebvre JL, Gordon LR, Granato M. 2009. Wnt signals organize synaptic prepattern and axon guidance 
K. Koles and V. Budnik

through the zebrafish unplugged/MuSK receptor. Neuron 61: 721-733.

Johnson EB, Hammer RE, Herz J. 2005. Abnormal development of the apical ectodermal ridge and polysyndactyly in Megf7-deficient mice. Hum Mol Genet 14: 3523-3538.

Kim N, Stiegler AL, Cameron TO, Hallock PT, Gomez AM, Huang JH, Hubbard SR, Dustin ML, Burden SJ. 2008. Lrp4 is a receptor for Agrin and forms a complex with MuSK. Cell 135: 334-342.

Klassen MP, Shen K. 2007. Wnt signaling positions neuromuscular connectivity by inhibiting synapse formation in C. elegans. Cell 130: 704-716.

Koon AC, Ashley J, Barria R, Dasgupta S, Brain R, Waddell S, Alkema MJ, Budnik V. 2011. Autoregulatory and paracrine control of synaptic and behavioral plasticity by octopaminergic signaling. Nat Neurosci 14: 190-199.

Korinek V, Barker N, Morin PJ, van Wichen D, de Weger R, Kinzler KW, Vogelstein B, Clevers H. 1997. Constitutive transcriptional activation by a $\beta$-catenin-Tcf complex in $\mathrm{APC}^{-/-}$colon carcinoma. Science 275: 1784-1787.

Korkut C, Ataman B, Ramachandran P, Ashley J, Barria R, Gherbesi N, Budnik V. 2009. Trans-synaptic transmission of vesicular Wnt signals through Evi/Wntless. Cell 139: 393-404.

Krylova O, Herreros J, Cleverley KE, Ehler E, Henriquez JP, Hughes SM, Salinas PC. 2002. WNT-3, expressed by motoneurons, regulates terminal arborization of neurotrophin-3-responsive spinal sensory neurons. Neuron 35: 1043-1056.

Kuhl M, Sheldahl LC, Park M, Miller JR, Moon RT. 2000. The Wnt $/ \mathrm{Ca}^{2+}$ pathway: A new vertebrate Wnt signaling pathway takes shape. Trends Genet 16: 279-283.

Kummer TT, Misgeld T, Sanes JR. 2006. Assembly of the postsynaptic membrane at the neuromuscular junction: Paradigm lost. Curr Opin Neurobiol 16: 74-82.

Lahey T, Gorczyca M, Jia XX, Budnik V. 1994. The Drosophila tumor suppressor gene dlgis required for normal synaptic bouton structure. Neuron 13: 823-835.

Li XM, Dong XP, Luo SW, Zhang B, Lee DH, Ting AK, Neiswender H, Kim CH, Carpenter-Hyland E, Gao TM, et al. 2008. Retrograde regulation of motoneuron differentiation by muscle $\beta$-catenin. Nat Neurosci 11: $262-268$.

Liebl FL, Wu Y, Featherstone DE, Noordermeer JN, Fradkin L, Hing H. 2008. Derailed regulates development of the Drosophila neuromuscular junction. Dev Neurobiol 68: $152-165$.

Liebl FL, McKeown C, Yao Y, Hing HK. 2010. Mutations in Wnt2 alter presynaptic motor neuron morphology and presynaptic protein localization at the Drosophila neuromuscular junction. PLoS ONE 5: e12778.

Lin W, Burgess RW, Dominguez B, Pfaff SL, Sanes JR, Lee KF. 2001. Distinct roles of nerve and muscle in postsynaptic differentiation of the neuromuscular synapse. Nature 410: $1057-1064$.

Lin W, Dominguez B, Yang J, Aryal P, Brandon EP, Gage FH, Lee KF. 2005. Neurotransmitter acetylcholine negatively regulates neuromuscular synapse formation by a Cdk5dependent mechanism. Neuron 46: 569-579.
Logan CY, Nusse R. 2004. The Wnt signaling pathway in development and disease. Annu Rev Cell Dev Biol 20: 781-810.

Lucas FR, Salinas PC. 1997. WNT-7a induces axonal remodeling and increases synapsin I levels in cerebellar neurons. Dev Biol 192: 31-44.

Lucas FR, Goold RG, Gordon-Weeks PR, Salinas PC. 1998 Inhibition of GSK-3 $\beta$ leading to the loss of phosphorylated MAP-1B is an early event in axonal remodelling induced by WNT-7a or lithium. J Cell Sci 111: 1351-1361.

Luo ZG, Wang Q, Zhou JZ, Wang J, Luo Z, Liu M, He X, Wynshaw-Boris A, Xiong WC, Lu B, et al. 2002. Regulation of AChR clustering by Dishevelled interacting with MuSK and PAK1. Neuron 35: 489-505.

Lyu J, Yamamoto V, Lu W. 2008. Cleavage of the Wnt receptor Ryk regulates neuronal differentiation during cortical neurogenesis. Dev Cell 15: 773-780.

Marie B, Pym E, Bergquist S, Davis GW. 2010. Synaptic homeostasis is consolidated by the cell fate gene gooseberry, a Drosophila pax3/7 homolog. J Neurosci 30: 8071-8082.

Masiakowski P, Yancopoulos GD. 1998. The Wnt receptor CRD domain is also found in MuSK and related orphan receptor tyrosine kinases. Curr Biol 8: R407.

Mathew D, Gramates LS, Packard M, Thomas U, Bilder D, Perrimon N, Gorczyca M, Budnik V. 2002. Recruitment of scribble to the synaptic scaffolding complex requires GUK-holder, a novel DLG binding protein. Curr Biol 12: 531-539.

Mathew D, Ataman B, Chen J, Zhang Y, Cumberledge S, Budnik V. 2005. Wingless signaling at synapses is through cleavage and nuclear import of receptor DFrizzled2. Science 310: 1344-1347.

Mettenleiter TC, Klupp BG, Granzow H. 2006. Herpesvirus assembly: A tale of two membranes. Curr Opin Microbiol 9: 423-429.

Miech C, Pauer HU, He X, Schwarz TL. 2008. Presynaptic local signaling by a canonical wingless pathway regulates development of the Drosophila neuromuscular junction. J Neurosci 28: 10875-10884.

Mlodzik M. 2002. Planar cell polarization: Do the same mechanisms regulate Drosophila tissue polarity and vertebrate gastrulation? Trends Genet 18: 564-571.

Moransard M, Borges LS, Willmann R, Marangi PA, Brenner HR, Ferns MJ, Fuhrer C. 2003. Agrin regulates rapsyn interaction with surface acetylcholine receptors, and this underlies cytoskeletal anchoring and clustering. $J$ Biol Chem 278: 7350-7359.

Mosca TJ, Schwarz TL. 2010. The nuclear import of Frizzled2-C by Importins- $\beta 11$ and $\alpha 2$ promotes postsynaptic development. Nat Neurosci 13: 935-943.

Moseley JB, Bartolini F, Okada K, Wen Y, Gundersen GG, Goode BL. 2007. Regulated binding of adenomatous polyposis coli protein to actin. J Biol Chem 282: 1266112668.

Mulligan KA, Fuerer C, Ching W, Fish M, Willert K, Nusse R. 2012. Secreted Wingless-interacting molecule (Swim) promotes long-range signaling by maintaining Wingless solubility. Proc Natl Acad Sci 109: 370-377. 
Nagel G, Ollig D, Fuhrmann M, Kateriya S, Musti AM, Bamberg E, Hegemann P. 2002. Channelrhodopsin-1: A light-gated proton channel in green algae. Science 296: 2395-2398.

Niehrs C. 2006. Function and biological roles of the Dickkopf family of Wnt modulators. Oncogene 25: 74697481.

Okada K, Inoue A, Okada M, Murata Y, Kakuta S, Jigami T, Kubo S, Shiraishi H, Eguchi K, Motomura M, et al. 2006. The muscle protein Dok-7 is essential for neuromuscular synaptogenesis. Science 312: 1802-1805.

Okerlund ND, Cheyette BN. 2011. Synaptic Wnt signaling - a contributor to major psychiatric disorders? J Neurodev Disord 3: $162-174$.

Packard M, Koo ES, Gorczyca M, Sharpe J, Cumberledge S, Budnik V. 2002. The Drosophila Wnt, Wingless, provides an essential signal for pre- and postsynaptic differentiation. Cell 111: 319-330.

Panakova D, Sprong H, Marois E, Thiele C, Eaton S. 2005. Lipoprotein particles are required for Hedgehog and Wingless signalling. Nature 435: 58-65.

Petersen SA, Fetter RD, Noordermeer JN, Goodman CS, DiAntonio A. 1997. Genetic analysis of glutamate receptors in Drosophila reveals a retrograde signal regulating presynaptic transmitter release. Neuron 19: 1237-1248.

Pinson KI, Brennan J, Monkley S, Avery BJ, Skarnes WC 2000. An LDL-receptor-related protein mediates Wnt signalling in mice. Nature 407: 535-538.

Ramirez-Weber FA, Kornberg TB. 1999. Cytonemes: Cellular processes that project to the principal signaling center in Drosophila imaginal discs. Cell 97: 599-607.

Rapti G, Richmond J, Bessereau JL. 2011. A single immunoglobulin-domain protein required for clustering acetylcholine receptors in C. elegans. EMBO J 30: 706-718.

Rattner A, Hsieh JC, Smallwood PM, Gilbert DJ, Copeland NG, Jenkins NA, Nathans J. 1997. A family of secreted proteins contains homology to the cysteine-rich ligandbinding domain of frizzled receptors. Proc Natl Acad Sci 94: $2859-2863$.

Reilein A, Nelson WJ. 2005. APC is a component of an organizing template for cortical microtubule networks. Nat Cell Biol 7: 463-473.

Roller RJ. 2008. Nuclear egress of herpes viruses. Virol Sin 23: 406-415.

Roos J, Hummel T, Ng N, Klambt C, Davis GW. 2000. Drosophila Futsch regulates synaptic microtubule organization and is necessary for synaptic growth. Neuron 26: 371-382.

Rosenberg MM, Yang F, Giovanni M, Mohn JL, Temburni MK, Jacob MH. 2008. Adenomatous polyposis coli plays a key role, in vivo, in coordinating assembly of the neuronal nicotinic postsynaptic complex. Mol Cell Neurosci 38: $138-152$.

Ruiz-Canada C, Ashley J, Moeckel-Cole S, Drier E, Yin J, Budnik V. 2004. New synaptic bouton formation is disrupted by misregulation of microtubule stability in aPKC mutants. Neuron 42: 567-580.

Sanes JR, Lichtman JW. 2001. Induction, assembly, maturation and maintenance of a postsynaptic apparatus. Nat Rev Neurosci 2: 791-805.
Schuster CM, Davis GW, Fetter RD, Goodman CS. 1996. Genetic dissection of structural and functional components of synaptic plasticity. I. Fasciclin II controls synaptic stabilization and growth. Neuron 17: 641-654.

Sigrist SJ, Reiff DF, Thiel PR, Steinert JR, Schuster CM. 2003. Experience-dependent strengthening of Drosophila neuromuscular junctions. J Neurosci 23: 6546-6556.

Smith MA, Yao YM, Reist NE, Magill C, Wallace BG, McMahan UJ. 1987. Identification of agrin in electric organ extracts and localization of agrin-like molecules in muscle and central nervous system. J Exp Biol 132: 223-230.

Speese SD, Budnik V. 2007. Wnts: Up-and-coming at the synapse. Trends Neurosci 30: 268-275.

Speese S, Ashley J, Jokhi V, Nunnari J, Barria R, Li Y, Ataman B, Koon AC, Chang HY, Li Q, et al. 2012. Nuclear envelope budding enables large ribonucleoprotein particle export during synaptic Wnt signaling. Cell (in press).

Stamos LJ, Weis WL. 2012. The beta-catenin destruction complex. Cold Spring Harb Perspect Biol doi: 10.1101. cshperspect.a007898.

Steinert JR, Kuromi H, Hellwig A, Knirr M, Wyatt AW, Kidokoro Y, Schuster CM. 2006. Experience-dependent formation and recruitment of large vesicles from reserve pool. Neuron 50: 723-733.

Su LK, Burrell M, Hill DE, Gyuris J, Brent R, Wiltshire R, Trent J, Vogelstein B, Kinzler KW. 1995. APC binds to the novel protein EB1. Cancer Res 55: 2972-2977.

Sugiura Y, Lin W. 2011. Neuron-glia interactions: The roles of Schwann cells in neuromuscular synapse formation and function. Biosci Rep 31: 295-302.

Szollosi D. 1965. Extrusion of nucleoli from pronuclei of the rat. J Cell Biol 25: 545-562.

Szollosi MS, Szollosi D. 1988. "Blebbing" of the nuclear envelope of mouse zygotes, early embryos and hybrid cells. J Cell Sci 91: 257-267.

Takada R, Satomi Y, Kurata T, Ueno N, Norioka S, Kondoh H, Takao T, Takada S. 2006. Monounsaturated fatty acid modification of Wnt protein: Its role in Wnt secretion. Dev Cell 11: 791-801.

Tamai K, Semenov M, Kato Y, Spokony R, Liu C, Katsuyama Y, Hess F, Saint-Jeannet JP, He X. 2000. LDL-receptorrelated proteins in Wnt signal transduction. Nature 407: $530-535$.

Temburni MK, Rosenberg MM, Pathak N, McConnell R, Jacob MH. 2004. Neuronal nicotinic synapse assembly requires the adenomatous polyposis coli tumor suppressor protein. J Neurosci 24: 6776-6784.

Thomas U, Kim E, Kuhlendahl S, Koh YH, Gundelfinger ED, Sheng M, Garner CC, Budnik V. 1997. Synaptic clustering of the cell adhesion molecule fasciclin II by discslarge and its role in the regulation of presynaptic structure. Neuron 19: 787-799.

Tian QB, Suzuki T, Yamauchi T, Sakagami H, Yoshimura Y, Miyazawa S, Nakayama K, Saitoh F, Zhang JP, Lu Y, et al 2006. Interaction of LDL receptor-related protein 4 (LRP4) with postsynaptic scaffold proteins via its C-terminal PDZ domain-binding motif, and its regulation by $\mathrm{Ca} / \mathrm{calmodulin}$-dependent protein kinase II. Eur J Neurosci 23: 2864-2876.

Valenzuela DM, Stitt TN, DiStefano PS, Rojas E, Mattsson K, Compton DL, Nunez L, Park JS, Stark JL, Gies DR, 
K. Koles and V. Budnik

et al. 1995. Receptor tyrosine kinase specific for the skeletal muscle lineage: expression in embryonic muscle, at the neuromuscular junction, and after injury. Neuron 15: $573-584$.

Van Amerongen R. 2012. Alternative Wnt pathways and receptors. Cold Spring Harb Perspect Biol doi: 10.1101. cshperspect.a007914.

van Amerongen R, Nusse R. 2009. Towards an integrated view of Wnt signaling in development. Development 136 3205-3214.

Wallace BG. 1986. Aggregating factor from Torpedo electric organ induces patches containing acetylcholine receptors, acetylcholinesterase, and butyrylcholinesterase on cultured myotubes. J Cell Biol 102: 783-794.

Wang J, Jing Z, Zhang L, Zhou G, Braun J, Yao Y, Wang ZZ. 2003. Regulation of acetylcholine receptor clustering by the tumor suppressor APC. Nat Neurosci 6: $1017-$ 1018.

Wang J, Ruan NJ, Qian L, Lei WL, Chen F, Luo ZG. 2008. Wnt/ $\beta$-catenin signaling suppresses Rapsyn expression and inhibits acetylcholine receptor clustering at the neuromuscular junction. J Biol Chem 283: 21668-21675.

Weatherbee SD, Anderson KV, Niswander LA. 2006. LDLreceptor-related protein 4 is crucial for formation of the neuromuscular junction. Development 133: $4993-$ 5000 .

Wehrli M, Dougan ST, Caldwell K, O'Keefe L, Schwartz S, Vaizel-Ohayon D, Schejter E, Tomlinson A, DiNardo S 2000. arrow encodes an LDL-receptor-related protein essential for Wingless signalling. Nature 407: 527-530.

Weston C, Gordon C, Teressa G, Hod E, Ren XD, Prives J. 2003. Cooperative regulation by Rac and Rho of agrininduced acetylcholine receptor clustering in muscle cells. J Biol Chem 278: 6450-6455.

Willert K, Nusse R. 2012. Wnt Proteins. Cold Spring Harb Perspect Biol doi: 10.1101/cshperspect.a007864.

Willert K, Brown JD, Danenberg E, Duncan AW, Weissman IL, Reya T, Yates JR III, Nusse R. 2003. Wnt proteins are lipid-modified and can act as stem cell growth factors. Nature 423: 448-452.
Worman HJ, Bonne G. 2007. “Laminopathies”: Awide spectrum of human diseases. Exp Cell Res 313: 2121-2133.

Wu CH, Nusse R. 2002. Ligand receptor interactions in the Wnt signaling pathway in Drosophila. J Biol Chem 277: 41762-41769.

Wu H, Xiong WC, Mei L. 2010. To build a synapse: Signaling pathways in neuromuscular junction assembly. Development 137: 1017-1033.

Yang X, Arber S, William C, Li L, Tanabe Y, Jessell TM, Birchmeier C, Burden SJ. 2001. Patterning of muscle acetylcholine receptor gene expression in of motor innervation. Neuron 30: 399-410.

Yoshihara CM, Hall ZW. 1993. Increased expression of the $43-\mathrm{kD}$ protein disrupts acetylcholine receptor clustering in myotubes. J Cell Biol 122: 169-179.

Yoshikawa S, McKinnon RD, Kokel M, Thomas JB. 2003. Wnt-mediated axon guidance via the Drosophila Derailed receptor. Nature 422: 583-588.

Zhang J, Lefebvre JL, Zhao S, Granato M. 2004. Zebrafish unplugged reveals a role for muscle-specific kinase homologs in axonal pathway choice. Nat Neurosci 7: 13031309.

Zhang B, Luo S, Dong XP, Zhang X, Liu C, Luo Z, Xiong WC, Mei L. 2007. $\beta$-Catenin regulates acetylcholine receptor clustering in muscle cells through interaction with Rapsyn. J Neurosci 27: 3968-3973.

Zhang B, Luo S, Wang Q, Suzuki T, Xiong WC, Mei L. 2008. LRP4 serves as a coreceptor of agrin. Neuron 60: 285-297.

Zhang W, Coldefy AS, Hubbard SR, Burden SJ. 2011. Agrin binds to the N-terminal region of Lrp4 protein and stimulates association between Lrp4 and the first immunoglobulin-like domain in muscle-specific kinase (MuSK). J Biol Chem 286: 40624-40630.

Zito K, Fetter RD, Goodman CS, Isacoff EY. 1997. Synaptic clustering of Fascilin II and Shaker: Essential targeting sequences and role of Dlg. Neuron 19: 1007-1016.

Zito K, Parnas D, Fetter RD, Isacoff EY, Goodman CS. 1999. Watching a synapse grow: Noninvasive confocal imaging of synaptic growth in Drosophila. Neuron 22: 719-729. 


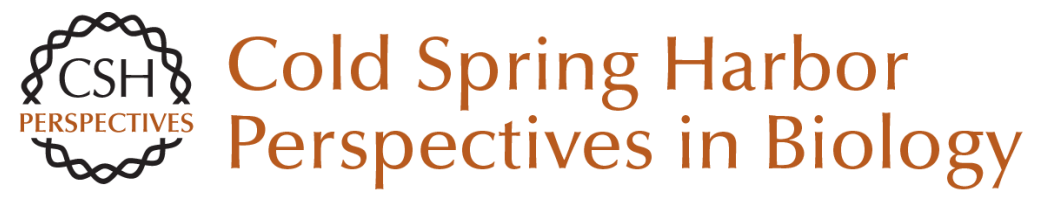

\section{Wnt Signaling in Neuromuscular Junction Development}

Kate Koles and Vivian Budnik

Cold Spring Harb Perspect Biol 2012; doi: 10.1101/cshperspect.a008045

Subject Collection Wnt Signaling

Wnt Signaling in Vertebrate Axis Specification Hiroki Hikasa and Sergei Y. Sokol

Secreted and Transmembrane Wnt Inhibitors and Activators Cristina-Maria Cruciat and Christof Niehrs

Wnt Signaling in Normal and Malignant

Hematopoiesis William Lento, Kendra Congdon, Carlijn Voermans, et al.

Frizzled and LRP5/6 Receptors for Wnt/ $\beta$-Catenin Signaling Bryan T. MacDonald and Xi He

TCF/LEFs and Wnt Signaling in the Nucleus Ken M. Cadigan and Marian L. Waterman

Alternative Wnt Pathways and Receptors Renée van Amerongen

$\beta$-Catenin-Dependent Wnt Signaling in C. elegans:

Teaching an Old Dog a New Trick Belinda M. Jackson and David M. Eisenmann

The Evolution of the Wnt Pathway Thomas W. Holstein
The $\beta$-Catenin Destruction Complex Jennifer L. Stamos and William I. Weis

Wnt Signaling in Skin Development, Homeostasis, and Disease Xinhong Lim and Roel Nusse

Wnt Signaling in Bone Development and Disease:

Making Stronger Bone with Wnts Jean B. Regard, Zhendong Zhong, Bart O. Williams, et al.

Targeting Wnt Pathways in Disease Zachary F. Zimmerman, Randall T. Moon and Andy J. Chien

Wnt Signaling in Mammary Glands: Plastic Cell

Fates and Combinatorial Signaling Caroline M. Alexander, Shruti Goel, Saja A. Fakhraldeen, et al.

Wnt Signaling and Injury Repair Jemima L. Whyte, Andrew A. Smith and Jill A. Helms

Wnt Signaling and Forebrain Development Susan J. Harrison-Uy and Samuel J. Pleasure

Wnt Signaling in Neuromuscular Junction Development Kate Koles and Vivian Budnik

For additional articles in this collection, see http://cshperspectives.cshlp.org/cgi/collection/

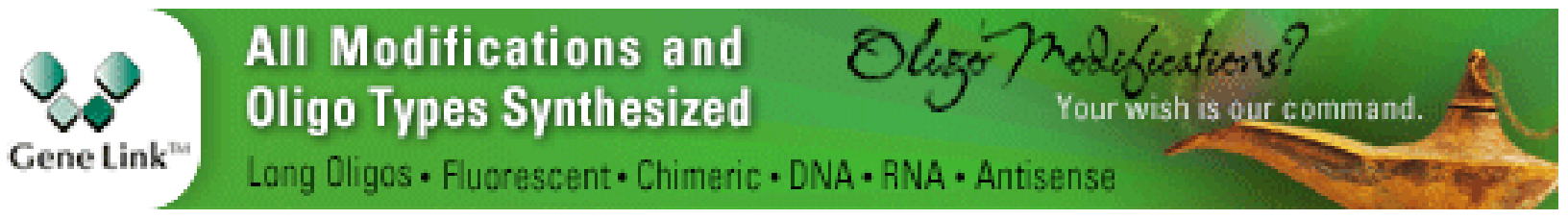

